\title{
MONETARY POLICY
} AND THE FINANCING OF FIRMS

by Fiorella De Fiore, Pedro Teles

and Oreste Tristani 
EUROSYSTEM

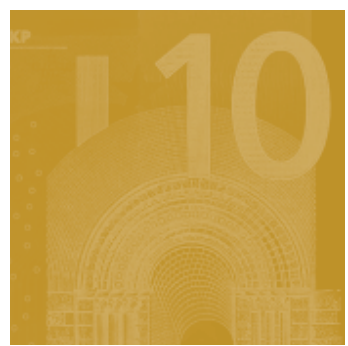

\title{
WORKING PAPER SERIES
} NO II 23 / DECEMBER 2009

\section{MONETARY POLICY AND THE FINANCING OF FIRMS'}

\author{
by Fiorella De Fiore? \\ Pedro Teles ${ }^{3}$ \\ and Oreste Tristani ${ }^{2}$
}
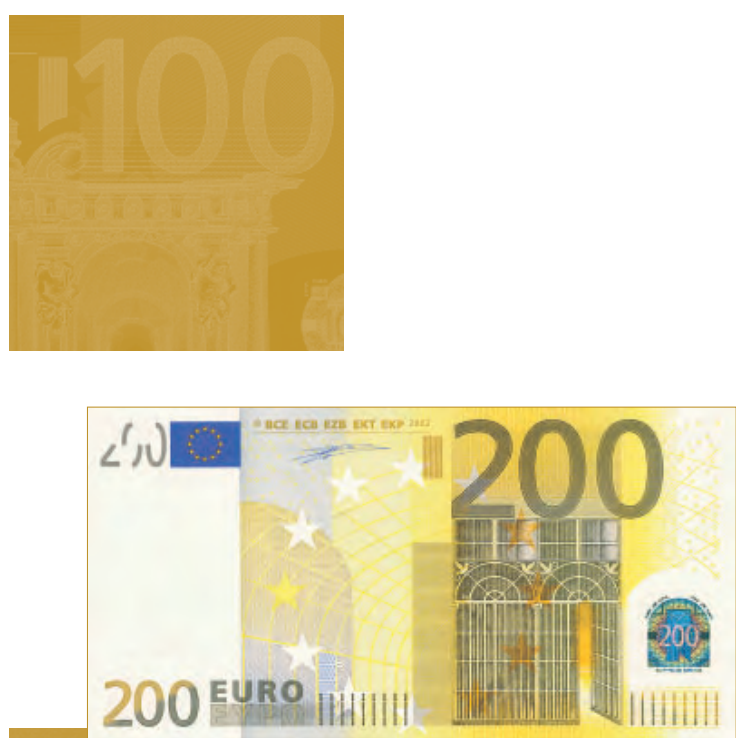

In 2009 all ECB

This paper can be downloaded without charge from http://www.ecb.europa.eu or from the Social Science Research Network electronic library at http://ssrn.com/abstract_id $=1515810$.

I We wish to thank John Leahy, Kosuke Aoki, Isabel Correia, Skander Van den Heuvel, Alistair Milne, Stephanie Schmitt-Grohe, Kevin Sheedy, and an anonymous referee, for very useful comments and suggestions. We also thank participants at seminars where this paper was presented. Teles gratefully acknowledges the financial support of Fundação de Ciência e Teconologia. The views expressed here are those of the authors and do not necessarily reflect those of the European Central Bank or of the Banco de Portugal. 2 European Central Bank, DG Research, Kaiserstrasse 29, D-603II Frankfurt am Main, Germany; e-mail: fiorella.de_fiore@ecb.europa.eu and oreste.tristani@ecb.europa.eu 3 Banco de Portugal, Universidade Catolica Portuguesa, and Centre for Economic Policy Research; 
(C) European Central Bank, 2009

Address

Kaiserstrasse 29

60311 Frankfurt am Main, Germany

Postal address

Postfach 160319

60066 Frankfurt am Main, Germany

Telephone

+496913440

Website

http://www.ecb.europa.eu

\section{Fax}

+496913446000

All rights reserved.

Any reproduction publication and reprint in the form of a different publication, whether printed or produced electronically, in whole or in part, is permitted only with the explicit written authorisation of the ECB or the author(s).

The views expressed in this paper do not necessarily reflect those of the European Central Bank

The statement of purpose for the ECB Working Paper Series is available from the ECB website, http://www.ecb.europa. eu/pub/scientific/wps/date/html/index. en.html

ISSN 1725-2806 (online) 


\section{CONTENTS}

Abstract

Non-technical summary

1 Introduction

2 Model

2.1 Households

2.2 Production

2.3 Entrepreneurs

2.4 Government

2.5 Equilibria

2.6 Optimal policy

3 Numerical results

3.1 Impulse responses under optimal policy

3.2 Optimal policy when a non-zero interest rate is optimal

3.3 Taylor rule policy

4 The case in which internal and external funds are perfect substitutes

4.1 Inflation stabilization is not optimal

4.2 The role of asymmetric information and monitoring costs

5 Conclusions

Appendix

References

European Central Bank Working Paper Series 


\begin{abstract}
How should monetary policy respond to changes in financial conditions? In this paper we consider a simple model where firms are subject to idiosyncratic shocks which may force them to default on their debt. Firms' assets and liabilities are denominated in nominal terms and predetermined when shocks occur. Monetary policy can therefore affect the real value of funds used to finance production. Furthermore, policy affects the loan and deposit rates. In our model, allowing for short-term inflation volatility in response to exogenous shocks can be optimal; the optimal response to adverse financial shocks is to lower interest rates, if not at the zero bound, and to engineer a short period of controlled inflation; the Taylor rule may implement allocations that have opposite cyclical properties to the optimal ones.
\end{abstract}

Keywords: Financial stability; debt deflation; bankruptcy costs; price level volatility; optimal monetary policy; stabilization policy.

JEL Classification: E20, E44, E52 


\section{NON-TECHNICAL SUMMARY}

How should monetary policy respond to financial shocks? How should it respond to real shocks, when financial conditions affect macroeconomic outcomes? Would a short-term deviation from price stability help the economic recovery after recessions induced by financial shocks? How relevant is the zero bound constraint on the nominal interest rate?

This paper tries to shed light on these questions based on a model where monetary policy has the ability to affect the financing conditions of firms. To analyze this particular channel of transmission of monetary policy, the paper relies on a simplified framework, which abstracts from other transmission channels. Our set-up has three distinguishing features. First, firms' internal and external sources of finance are imperfect substitutes. This is due to the presence of information asymmetries, such that banks cannot observe firms' productivity without exercising a costly monitoring activity. Second, both firms' internal funds and the loans they receive from banks are denominated in nominal terms - hence affected by inflation. Third, the quantity of bank loans and the interest rate on those loans are predetermined and cannot be adjusted after the occurrence of aggregate shocks.

In this environment, allowing for short-term inflation volatility in response to exogenous shocks can be optimal. In response to technology shocks, for example, changes in the price level can facilitate the necessary adjustment in the real value of firms' internal and external funds. If the shock is negative and persistent, a very short-lived inflationary episode would be sufficient to ensure the most efficient economic outcome. Along the adjustment path, the policy interest rate, credit spreads, financial markups, leverage, and bankruptcy rates would be completely stabilized.

The optimal response to an adverse financial shock - namely a shock that reduces firms' internal funds and increases firms' leverage - also warrants a short-lived increase in inflation. The increase in inflation mitigates the adverse consequences of the shock on bankruptcy rates and allows firms to de-leverage more quickly.

In the baseline version of our model, the optimal deposit rate is zero, corresponding to the Friedman rule. When the nominal interest rate is not at the lower bound and can be adjusted in response to shocks, it should be lowered after adverse financial shocks. Reducing the nominal interest rate allows policy to speed up the adjustment process and to mitigate the consequences of these shocks on output. For instance, a shock that reduces the value of internal funds is persistently contractionary when the short term nominal rate is at zero, while it is less contractionary and produces very short-lived effects on output when the short term rate can be reduced.

Compared to these optimal policy responses, following a simple Taylor-type rule can be costly, in the sense of inducing persistent deviations in real variables from their optimal values and more volatile bankruptcy rates. In response to technology shocks, bankruptcies are countercyclical when policy follows a Taylor rule, while they are acyclical under optimal policy. In response to a financial 
shock that reduces the value of internal funds, the Taylor rule produces deflation initially, thus increasing the real value of nominal debt and leading to a much larger increase in leverage. As a result, bankruptcy rates are higher than under optimal policy. 


\section{Introduction}

During financial crises, credit conditions tend to worsen for all agents in the economy. In the press, there are frequent calls for a looser monetary policy stance, on the grounds that this helps avoid a deep recession and the risks of a credit crunch. The intuitive argument is that lower interest rates tend to make it easier for firms to obtain external finance, thus countering the effects of the tightening of credit standards. Arguments tracing back to Fisher (1933) can also be used to call for some degree of inflation during financial crises, so as to avoid an excessive increase in firms' leverage through a devaluation of their nominal liabilities.

It is less clear, however, whether these arguments would withstand a more formal analysis. In this paper, we present a model that can be used to evaluate them. More specifically, we address the following questions: How should monetary policy respond to financial shocks? How should it respond to other shocks, when financial conditions affect macroeconomic outcomes? Should monetary policy engineer some inflation during recessions? How relevant is the zero bound on the nominal interest rate?

To answer these questions, we use a model where monetary policy has the ability to affect the financing conditions of firms. Our set-up has three distinguishing features. First, firms' internal and external funds are imperfect substitutes. This is due to the presence of information asymmetries between firms and banks regarding firms' productivity, and to the fact that monitoring is a costly activity for banks. Second, firms' internal and external funds are nominal assets. Third, those funds, both internal and external, as well as the interest rate on bank loans, are predetermined when aggregate shocks occur.

We find that, for the Ramsey planner, allowing for short-term inflation volatility in response to exogenous shocks can be optimal. In response to technology shocks, for example, the price level should move to adjust the real value of total funds. If the shock is negative, the price level increases on impact to lower real funds as well as the real wage. Subsequently, the price level falls in order to increase the real wage at the same pace as productivity, in the convergence back to the steady state. Along the adjustment path, deposit and loan rates, spreads, financial markups, leverage, and bankruptcy rates remain stable. Therefore, under the optimal policy, and if technology shocks were the only shocks hitting the economy, bankruptcies would be acyclical. 
The optimal response to a financial shock that reduces firms' internal funds, increasing firms' leverage, also involves an increase in the price level on impact, in order to lower real funds and the real wage. The short period of controlled inflation mitigates the adverse consequences of the shock on bankruptcy rates and allows firms to de-leverage more quickly.

In the baseline version of our model, the optimal deposit rate is zero, corresponding to the Friedman rule. Because assets are nominal and predetermined, a set path for the nominal interest rate does not pin down equilibrium allocations. Policy can additionally affect allocations through ex-post volatility of the price level.

To analyze the optimal interest rate reaction to shocks, we introduce government consumption as an exogenous share of production. This assumption generates a rationale for proportionate taxation. The nominal interest rate acts as a tax on consumption and therefore the optimal steady-state interest rate becomes positive - the Friedman rule is no longer optimal.

When the optimal average interest rate is away from the lower bound, it may be optimal for the interest rate to respond to shocks. This is indeed the case for financial shocks, but not for technology shocks. In response to technology shocks, it is optimal to keep rates constant even if they could be lowered. For financial shocks, the flexibility of moving the nominal interest rate downwards allows policy to speed up the adjustment process. Moreover, the effect of these shocks on output can be considerably mitigated. For instance, a shock that reduces the availability of internal funds is persistently contractionary when the short term nominal rate is kept fixed at zero, while it is less contractionary and has very short-lived effects on output when the average interest rate is away from the lower bound and the short term nominal rate is reduced.

Compared to the optimal Ramsey plan, a policy response according to a simple Taylortype rule can be costly, in the sense of inducing more persistent deviations in real variables from their optimal values and higher bankruptcy rates. In response to technology shocks, bankruptcies become countercyclical under the simple rule. In response to a financial shock that reduces internal funds, there is deflation initially, which increases the real value of total funds and leads to a much larger increase in leverage. The reduction in output is smaller than under the optimal policy and markups decrease, inducing higher bankruptcy rates.

In order to understand the mechanisms responsible for these results, we analyze a simplified model in which internal and external funds are perfect substitutes (i.e. monitoring costs are 
zero). We use this model to illustrate that the two assumptions of nominal denomination and predetermination of the funds used to finance production are sufficient conditions for changes in the price level to affect allocations. For this specific case, we show that, in response to a technology shock, optimal monetary policy aims at keeping the nominal wage constant. This is achieved by inducing movements in the price level such that the real wage adjusts oneto-one to productivity. Because, under log-linear preferences, labor does not move, nominal predetermined funds are ex-post optimal.

This simplified case also highlights two advantages of the more general model with asymmetric information and monitoring costs. The first one is to allow for policy analysis in response to financial shocks. Financial shocks are indeed hard to think of in the simple environment in which internal and external funds are perfect substitutes. The second advantage of the model with asymmetric information and monitoring costs is to amplify the reaction of the economy to shocks, when monetary policy follows a simple rule.

This paper contributes to the literature that analyzes the effects of financial factors on the transmission of shocks. Financial factors play a role because of agency costs, as in Bernanke et al. (1999) and Carlstrom and Fuerst (1997, 1998, 2001). In Bernanke et al. (1999), agency costs are added to an otherwise standard New-Keynesian model, where monetary policy has real effects because of the presence of sticky prices. In Carlstrom and Fuerst (2001), prices are flexible but money affects real activity because of a cash-in-advance constraint on households' purchases. In our model, prices are flexible but monetary policy has real effects because firms must use funds to pay wages and these funds are nominal and predetermined.

Our work is most closely related to a recent literature that analyzes optimal monetary policy in models with financial frictions (see e.g. Ravenna and Walsh (2006), Curdia and Woodford (2008), De Fiore and Tristani (2008), Carlstrom et al. (2009), and Faia (2009)). ${ }^{1}$ Ravenna and Walsh (2006) characterize optimal monetary policy when firms need to borrow to finance production, but there is no default risk and the cost of financing is the risk-free rate. Curdia and Woodford (2008) consider a model where financial frictions matter for the allocation of resources, because of the heterogeneity in households' spending opportunities. In their setup, credit spreads arise because loans are costly to produce, but they are linked to macroeconomic conditions through a flexible reduced-form function. Instead, credit spreads emerge as the outcome of an optimal financial contract in De Fiore and Tristani (2008) and

\footnotetext{
${ }^{1}$ See also Christiano et al. (2003).
} 
Faia (2009), while Carlstrom et al. (2009) model agency costs as a constraint on the firm's hiring of labor. In all these papers, prices are assumed to be sticky. The main lesson from this literature is that, in the presence of financial frictions, both financial and non-financial shocks create a trade-off between inflation and output gap stabilization. Although perfect price stability is in general not optimal, under reasonable calibrations, the welfare gains associated to price stability are much larger than those associated to mitigating the financial distortions.

The main distinguishing feature between these models and ours is the assumption that firms' financing conditions are predetermined when aggregate shocks occur. In our model, the stock of internal funds, the amount of banks loans, and the interest rate on bank loans are not contingent on the realization of aggregate shocks. This enables us to study how changes in the inflation rate may have an impact on the dynamics of firms' leverage. To study this particular channel of transmission of monetary policy, we abstract from other frictions, such as sticky prices.

Building upon the Bernanke et al. (1999) setup, Gilchrist and Leahy (2002) and Faia and Monacelli (2007) find that the presence of financial frictions does not provide a justification for reacting to asset prices directly. In reaction to a technology shock and to an expected technology shock, monetary policy should react to asset prices, but a policy that reacts strongly to inflation closely approximates the optimal policy. In our model, a policy that stabilizes prices performs slightly better than a simple Taylor rule that does not react aggressively to inflation. For the reasons discussed above, however, an aggressive policy response to inflation remains largely sub-optimal in our model.

The paper proceeds as follows. In section 2, we outline the environment and describe the equilibria. Then, we derive implementability conditions and we characterize optimal monetary policy. In section 3, we provide numerical results on the response of the economy to various shocks. We compare the case where optimal interest rate policy is the Friedman rule to the case where, because government consumption is assumed to be a fixed share of output, the optimal average interest rate is away from zero. We describe results both under the optimal monetary policy and a sub-optimal (Taylor) rule. In section 4, we analyze a simple model in which internal and external funds are perfect substitutes, and use it to provide some intuition on the results obtained for the general model. In section 5 , we conclude. 


\section{Model}

We consider a model where firms need internal and external funds to produce and they fail if they are not able to repay their debts. Both internal funds and firm debt are nominal assets. There is a goods market at the beginning of the period and an assets market at the end, ${ }^{2}$ where funds are decided for the following period. Funds are predetermined.

Production uses labor only with a linear technology. Aggregate productivity is stochastic. In addition, each firm faces an idiosyncratic shock whose realization is private information.

The households have preferences over consumption, labor and real money. For convenience we assume separability for the utility in real balances. ${ }^{3}$

Banks are financial intermediaries. They are zero profit, zero risk operations. Banks take deposits from households and allocate them to entrepreneurs on the basis of a debt contract where the entrepreneurs repay their debts if production is sufficient and default otherwise, handing in total production to the banks, provided these pay the monitoring costs. Because there is aggregate uncertainty, we assume that the government can make lump sum transfers between the households and the banks that ensure that banks have zero profits in every state. ${ }^{4}$ This way the banks are able to pay a risk free rate on deposits.

Entrepreneurs need to borrow in advance to finance production. The payments on outstanding debt are not state dependent. Entrepreneurs are risk neutral, patient, agents, that die with some probability. Their assets are seized at the time of death. In equilibrium they postpone consumption indefinitely. The tax on their assets at the time of death ensures that there is always a need for external funds.

The banks are owned, but not controlled, ${ }^{5}$ by the entrepreneurs. They behave as risk neutral agents, which is convenient since the financial contract is then between two risk neutral agents.

\footnotetext{
${ }^{2}$ This is the timing of transactions in Svensson (1985).

${ }^{3}$ We also assume a negligible contribution of real balances to welfare. This does not mean that the economy is cashless since firms face a cash-in-advance constraint.

${ }^{4} \mathrm{We}$ assume that the monitoring activities of banks can be observed, in order to keep the incentives to monitor unaffected by the insurance scheme. This amounts to assuming that bank supervision can be exercized at zero cost.

${ }^{5}$ Each entrepreneur owns an arbitrarily small share of each bank.
} 
Monetary policy can affect the real value of total funds available for the production of firms, but it can also affect the real value of debt that needs to be repaid. Furthermore, monetary policy also affects the deposit and loan rates.

\section{$2.1 \quad$ Households}

At the end of period $t$ in the assets market, households decide on holdings of money $M_{t}$ that they will be able to use at the beginning of period $t+1$ in the goods market, and on one-period deposits denominated in units of currency $D_{t}$ that will pay $R_{t}^{d} D_{t}$ in the assets market in period $t+1$. Deposits are riskless, in the sense that banks do not fail. The households also decide on a portfolio of nominal state-contingent bonds, each paying a unit of currency in a particular state in period $t+1$. The state-contingent bonds cost $E_{t} Q_{t, t+1} S_{t+1}$, where $Q_{t, t+1}$ is the price in units of money at $t$ of each bond normalized by the conditional probability of occurrence of the state at $t+1$.

The budget constraint at period $t$ is

$$
M_{t}+E_{t} Q_{t, t+1} S_{t+1}+D_{t} \leq S_{t}+R_{t-1}^{d} D_{t-1}+M_{t-1}-P_{t} c_{t}+W_{t} n_{t}-T_{t}^{h},
$$

where $c_{t}$ is the amount of the final consumption good purchased, $P_{t}$ is its price, $n_{t}$ is hours worked, $W_{t}$ is the nominal wage, and $T_{t}^{h}$ are lump-sum nominal taxes collected by the government.

The household's problem is to maximize utility, defined as

$$
E_{0}\left\{\sum_{0}^{\infty} \beta^{t}\left[u\left(c_{t}, m_{t}\right)-\alpha n_{t}\right]\right\},
$$

subject to (1) and a no-Ponzi games condition. Here $u_{c}>0, u_{m} \geq 0, u_{c c}<0, u_{m m}<0, \alpha>0$ and $m_{t} \equiv M_{t-1} / P_{t}$ denotes real balances. Throughout we will assume that the utility function is separable in real money, $m_{t}$, and that the contribution of money to welfare is negligible.

Optimality requires that the following conditions must hold:

$$
\begin{gathered}
\frac{u_{c}(t)}{\alpha}=\frac{P_{t}}{W_{t}}, \\
\frac{u_{c}(t)}{\beta u_{c}(t+1)}=Q_{t, t+1}^{-1} \frac{P_{t}}{P_{t+1}}, \\
\frac{u_{c}(t)}{P_{t}}=R_{t}^{d} E_{t} \frac{\beta u_{c}(t+1)}{P_{t+1}}, \\
E_{t} \frac{u_{m}(t+1)}{P_{t+1}}=E_{t} \frac{u_{c}(t+1)}{P_{t+1}}\left(R_{t}^{d}-1\right) .
\end{gathered}
$$




\subsection{Production}

The production sector is composed of a continuum of firms, indexed by $i \in[0,1]$. Each firm is endowed with a stochastic technology that transforms $N_{i, t}$ units of labor into $\omega_{i, t} A_{t} N_{i, t}$ units of output. The random variable $\omega_{i, t}$ is i.i.d. across time and across firms, with distribution $\Phi$, density $\phi$, mean 1 and standard deviation $\sigma_{\omega_{i, t}} \cdot A_{t}$ is an $\operatorname{AR}(1)$ aggregate productivity shock. The shock $\omega_{i, t}$ is private information, but its realization can be observed by the financial intermediary at the cost of a share $\mu$ of the firm's output.

The firms decide in the assets market at $t-1$ the amount of internal funds to be available in period $t, Z_{i, t-1}$. Lending occurs through the financial intermediary. The existence of aggregate shocks occurring during the duration of the contract implies that the intermediary's return from the lending activity is not safe, regardless of its ability to differentiate across the continuum of firms facing i.i.d. shocks. We assume the existence of a deposit insurance scheme that the government implements by completely taxing away the intermediary's profits whenever the aggregate shock is relatively high, and by providing subsidies up to the point where profits are zero when the aggregate shock is relatively low. Such scheme is financed with lump-sum taxes and transfers to the household. It guarantees that the intermediary is always able to repay the safe return to the household, thus insuring households' deposits from aggregate risk.

\subsubsection{The financial contract}

The firms must pay wages before receiving the sales from production. They have to bring in nominal funds from the previous period in order to do so. This amounts to having the firms decide the wage bill in advance. Each firm is, thus, restricted to hire and pay wages according to

$$
W_{t} N_{i, t} \leq X_{i, t-1}
$$

where $X_{i, t-1}$ are total funds, internal plus external, decided at the assets market in period $t-1$, to be available in period $t$. The firms have internal funds $Z_{i, t-1}$ and borrow $X_{i, t-1}-Z_{i, t-1}$.

The loan contract stipulates a payment of $R_{i, t-1}^{l}\left(X_{i, t-1}-Z_{i, t-1}\right)$, where $R_{i, t-1}^{l}$ is not contingent on the state at $t$, when the firm is able to meet those payments, i.e. when $\omega_{i, t} \geq \bar{\omega}_{i, t}$, where $\bar{\omega}_{i, t}$ is the minimum productivity level such that the firm is able to pay the fixed return to the bank, so that

$$
P_{t} A_{t} \bar{\omega}_{i, t} N_{i, t}=R_{i, t-1}^{l}\left(X_{i, t-1}-Z_{i, t-1}\right) .
$$


Otherwise the firm goes bankrupt, and hands out all the production $P_{t} A_{t} \omega_{i, t} N_{i, t}$. In this case, a constant fraction $\mu_{t}$ of the firm's output is destroyed in monitoring, so that the bank gets $\left(1-\mu_{t}\right) P_{t} A_{t} \omega_{i, t} N_{i, t}$.

Define the average share of production accruing to the firms and to the bank, respectively, after the repayment of the debt, as

$$
f\left(\bar{\omega}_{i, t}\right)=\int_{\bar{\omega}_{i, t}}^{\infty}\left(\omega_{i, t}-\bar{\omega}_{i, t}\right) \Phi(d \omega) .
$$

and

$$
g\left(\bar{\omega}_{i, t} ; \mu_{t}\right)=\int_{0}^{\bar{\omega}_{i, t}}\left(1-\mu_{t}\right) \omega_{i, t} \Phi(d \omega)+\int_{\bar{\omega}_{i, t}}^{\infty} \bar{\omega}_{i, t} \Phi(d \omega) .
$$

Total output is split between the firm, the bank, and monitoring costs

$$
f\left(\bar{\omega}_{i, t}\right)+g\left(\bar{\omega}_{i, t} ; \mu_{t}\right)=1-\mu_{t} G\left(\bar{\omega}_{i, t}\right),
$$

where $G\left(\bar{\omega}_{i, t}\right)=\int_{0}^{\bar{\omega}_{i, t}} \omega_{i, t} \Phi(d \omega)$. On average, $\mu_{t} G\left(\bar{\omega}_{i, t}\right)$ of output is lost in monitoring.

The optimal contract is a vector $\left(R_{i, t-1}^{l}, X_{i, t-1}, \bar{\omega}_{i, t}, N_{i, t}\right)$ that solves the following problem. Maximize the expected production accruing to firms, after repaying the debt,

$$
\max E_{t-1}\left[f\left(\bar{\omega}_{i, t}\right) P_{t} A_{t} N_{i, t}\right]
$$

subject to

$$
\begin{aligned}
W_{t} N_{i, t} & \leq X_{i, t-1} \\
E_{t-1}\left[g\left(\bar{\omega}_{i, t} ; \mu_{t}\right) P_{t} A_{t} N_{i, t}\right] & \geq R_{t-1}^{d}\left(X_{i, t-1}-Z_{i, t-1}\right) \\
E_{t-1}\left[f\left(\bar{\omega}_{i, t}\right) P_{t} A_{t} N_{i, t}\right] & \geq R_{t-1}^{d} Z_{i, t-1}
\end{aligned}
$$

where $g\left(\bar{\omega}_{i, t} ; \mu_{t}\right)$ and $f\left(\bar{\omega}_{i, t}\right)$ are given by (9) and (10), respectively, and $\bar{\omega}_{i, t}$ is given by (8). ${ }^{6}$

The informational structure in the economy corresponds to a costly state verification (CSV) problem. The optimal contract maximizes the entrepreneur's expected return subject to the

\footnotetext{
${ }^{6}$ The problem is written under the assumption that it is optimal to produce, rather than just hold the funds.
} The contract also specifies what happens if the firm does not produce. If, in case the firm does not produce, the bank monitors and takes all the funds, then the firm will produce. This is optimal for both the firm and the bank as long as $\left[1-\mu_{t} G\left(\bar{\omega}_{t}\right)\right] P_{t} A_{t} N_{i, t} \geq X_{i, t-1}$. If it is optimal to produce, then the financial constraint (11) holds with equality, so that it is optimal to produce as long as $\frac{P_{t} A_{t}}{W_{t}} \geq \frac{1}{1-\mu_{t} G\left(\bar{\omega}_{t}\right)}$. As long as the economy is sufficiently away from the first best (because the average deposit rate and/or the credit spreads are high enough), this condition will be satisfied. 
borrowing constraint for firms, (11), the financial intermediary receiving an amount not lower on average than the repayment requested by the household (the safe return on deposits), (12), and the entrepreneur being willing to sign the contract, (13).

The decisions on $X_{i, t-1}$ and $Z_{i, t-1}$ are made in period $t-1$ at the assets market. We can replace $N_{i, t}=\frac{X_{i, t-1}}{W_{t}}$ and divide the constraints by $X_{i, t-1}$ to get

$$
\max E_{t-1}\left[\frac{P_{t} A_{t}}{W_{t}} X_{i, t-1} f\left(\bar{\omega}_{i, t}\right)\right]
$$

subject to

$$
\begin{aligned}
E_{t-1}\left[\frac{P_{t} A_{t}}{W_{t}} g\left(\bar{\omega}_{i, t} ; \mu_{t}\right)\right] & \geq R_{t-1}^{d}\left(1-\frac{Z_{i, t-1}}{X_{i, t-1}}\right) \\
E_{t-1}\left[\frac{P_{t} A_{t}}{W_{t}} f\left(\bar{\omega}_{i, t}\right)\right] & \geq R_{t-1}^{d} \frac{Z_{i, t-1}}{X_{i, t-1}}
\end{aligned}
$$

where $f\left(\bar{\omega}_{i, t}\right)$ and $g\left(\bar{\omega}_{i, t} ; \mu_{t}\right)$ are given by (9) and (10), respectively, and where $\bar{\omega}_{i, t}$, defined by (8), can be rewritten as $\bar{\omega}_{i, t}=\frac{R_{i, t-1}^{l}}{\frac{P_{t} A_{t}}{W_{t}}}\left(1-\frac{Z_{i, t-1}}{X_{i, t-1}}\right)$.

Given that $Z_{i, t-1}$ is exogenous to this problem and is predetermined, we can multiply and divide the objective by $Z_{i, t-1}$, so that the problem is written in terms of $\frac{Z_{i, t-1}}{X_{i, t-1}}, R_{i, t-1}^{l}$, and $\bar{\omega}_{i, t}$, only. The objective and the constraints of the problem are the same for all firms. The only firm specific variable would be $Z_{i, t-1}$ in the objective, but this would be irrelevant for the maximization problem. Hence, the solution for $\frac{Z_{i, t-1}}{X_{i, t-1}}, R_{i, t-1}^{l}$, and $\bar{\omega}_{i, t}$ is the same across firms.

Define $z_{t-1} \equiv \frac{Z_{i, t-1}}{X_{i, t-1}}$ and $v_{t} \equiv \frac{P_{t} A_{t}}{W_{t}}$. We can then rewrite $\bar{\omega}_{i, t}$ as

$$
\bar{\omega}_{i, t} \equiv \bar{\omega}_{t}=\frac{R_{t-1}^{l}\left(1-z_{t-1}\right)}{v_{t}} .
$$

This condition, defining the bankruptcy threshold, together with the first-order conditions of the optimal contract problem, which can be written as ${ }^{7}$

$$
E_{t-1}\left[v_{t} f\left(\bar{\omega}_{t}\right)\right]=\frac{R_{t-1}^{d}}{1-\frac{E_{t-1}\left[\mu_{t} \bar{\omega}_{t} \phi\left(\bar{\omega}_{t}\right)\right]}{E_{t-1}\left[1-\Phi\left(\bar{\omega}_{t}\right)\right]}} z_{t-1}
$$

and

$$
E_{t-1}\left[v_{t} g\left(\bar{\omega}_{t} ; \mu_{t}\right)\right]=R_{t-1}^{d}\left(1-z_{t-1}\right),
$$

characterize the optimal $\left(R_{t-1}^{l}, z_{t-1}, \bar{\omega}_{t}\right)$.

\footnotetext{
${ }^{7}$ This is shown in Appendix A.1
} 


\section{$2.3 \quad$ Entrepreneurs}

The assumptions on the entrepreneurs are as in Carlstrom et al. (2009). Entrepreneurs die with probability $\gamma_{t}$. They have linear preferences over consumption with rate of time preference $\beta^{e}$. At the time of death, the funds of the entrepreneurs are seized and transferred to the households. We assume $\beta^{e}$ sufficiently high so that the return on internal funds is always higher than the preference discount, adjusted for the steady state probability of death, $\frac{1}{\beta^{e}(1-\gamma)}$. It follows that the entrepreneurs postpone consumption indefinitely. When entrepreneurs die, or go bankrupt, they are reborn, or restart, with $\varepsilon$ funds, that can be made arbitrarily small, transferred to them from the households.

The accumulation of internal funds is given by

$$
Z_{t}=f\left(\bar{\omega}_{t}\right) P_{t} A_{t} N_{t}-T_{t}^{e}
$$

The tax revenues are

$$
T_{t}^{e}=\gamma_{t} f\left(\bar{\omega}_{t}\right) P_{t} A_{t} N_{t}
$$

They are transferred to the households or used for government consumption. The accumulation of funds can then be written as

$$
Z_{t}=\left(1-\gamma_{t}\right) f\left(\bar{\omega}_{t}\right) \frac{v_{t}}{z_{t-1}} Z_{t-1}
$$

In steady state the real assets of the entrepreneurs must be constant. This means that the net return, after taxes, must be zero. This implies that the coefficient $\beta^{e}$ must be greater than one, even if, the rate of time preference adjusted for the probability of death is still less than one, $\beta^{e}(1-\gamma)<1$.

\subsection{Government}

The accumulation of liabilities by the government is governed by the period $t$ constraint

$$
M_{t}^{s}+E_{t} Q_{t, t+1} S_{t+1}^{s} \geq S_{t}^{s}+M_{t-1}^{s}+g P_{t} A_{t} N_{t}\left[1-\mu_{t} G\left(\bar{\omega}_{t}\right)\right]-T_{t}
$$

where $T_{t}=T_{t}^{h}+T_{t}^{e}$, and $M_{t}^{s}$ and $S_{t+1}^{s}$ are the supply of money and state contingent assets, respectively. We assume that government consumption is a share $g$ of production net of the monitoring costs. 


\subsection{Equilibria}

The equilibrium conditions are given by equations (3)-(6), (7) holding with equality, (17), (18), (19),

$$
Z_{i, t}=z_{t} X_{i, t}
$$

together with (22), the resource constraints

$$
c_{t}=(1-g) A_{t} N_{t}\left[1-\mu_{t} G\left(\bar{\omega}_{t}\right)\right],
$$

and the remaining market clearing conditions

$$
\begin{gathered}
M_{t}+Z_{t}=M_{t}^{s} \\
S_{t}=S_{t}^{s} \\
D_{t}=X_{t}-Z_{t}, \\
\int N_{i, t} d i=N_{t}=n_{t}
\end{gathered}
$$

where $\int Z_{i, t} d i=Z_{t}, \int X_{i, t} d i=X_{t}$, and where $f\left(\bar{\omega}_{t}\right)$ and $g\left(\bar{\omega}_{t} ; \mu_{t}\right)$ are given by (9) and (10), respectively, with $\bar{\omega}_{t}$ replacing $\bar{\omega}_{i t}$.

Aggregating across firms and imposing market clearing, we can write conditions (7) and $(24)$ as

$$
\frac{Z_{t-1}}{P_{t}}=z_{t-1} \frac{A_{t}}{v_{t}} n_{t}
$$

and

$$
z_{t}=\frac{Z_{t}}{X_{t}}
$$

We can also use the definition of $v_{t}$ in equation (3), (18) and (19), and combine these last two equations, together with $f\left(\bar{\omega}_{t}\right)=1-\mu_{t} G\left(\bar{\omega}_{t}\right)-g\left(\bar{\omega}_{t} ; \mu_{t}\right)$, to obtain

$$
E_{t-1}\left[\frac{u_{c}(t) A_{t}}{\alpha}\left[1-\mu_{t} G\left(\bar{\omega}_{t}\right)-f\left(\bar{\omega}_{t}\right) \frac{E_{t-1}\left[\mu_{t} \bar{\omega}_{t} \phi\left(\bar{\omega}_{t}\right)\right]}{E_{t-1}\left[1-\Phi\left(\bar{\omega}_{t}\right)\right]}\right]\right]=R_{t-1}^{d}, t \geq 1 .
$$

The equilibrium conditions are summarized in Appendix A.2, where we also show that, given a set path for the price level, there is a unique equilibrium for all the other variables. 


\subsection{Optimal policy}

We consider optimal Ramsey policy, with commitment. The objective is to maximize the welfare of the households. The entrepreneurs always consume zero, and therefore their weight in the welfare function does not matter. ${ }^{8}$ The assumption of commitment is relevant since the Ramsey policy is not time consistent. At time zero it is possible to use price level policy to, once and for all, lower the distortion associated with the costly state verification (and limited internal funds). We abstract from the optimal policy at time zero, in accordance with the timeless perspective in Woodford (2003).

We have assumed that government consumption is a share of production net of monitoring costs. This assumption has important implications for the optimal average nominal interest rate. Since a share of resources $g$ are wasted, it is optimal to distort production at a rate that is approximately equal to $g$. When $g=0,{ }^{9}$ we can show analytically that the Friedman rule is optimal in steady state, $R^{d}=1$. The Friedman rule is also optimal in response to shocks, in the calibrated version we analyze below. ${ }^{10}$

When $g>0$, it is optimal to distort the consumption-leisure margin, even if lump-sum taxes are available. Since the nominal interest rate acts as a consumption tax, it is optimal to set it higher than zero. ${ }^{11}$

Setting the path for the nominal interest rate does not pin down equilibrium allocations. Because the funds are nominal and predetermined, there is still a role for policy. For instance, in response to a technology shock, the optimal price level policy is aimed at keeping the nominal wage constant. The price level adjusts so that the real wage moves with productivity. As a

\footnotetext{
${ }^{8}$ The alternative approach would be to assume that entrepreneurs also consume and to give them a weight in the welfare function. The weights would be arbitrary, though, and the results would be much harder to interpret. They would envolve distribution considerations across the different agents, that are not particularly interesting in this set up. We do not want to think of the entrepreneurs as actual risk neutral agents, that insure risk averse households, consume and have a weight in the welfare function, but rather as a modelling device to introduce the external finance premium.

${ }^{9}$ If the level, and not the share, of government consumption was exogenous, the results would be as in the case of $g=0$.

${ }^{10}$ This is the case if shocks are small, but not necessarily otherwise.

${ }^{11}$ This is not a justification for positive average nominal interest rates, but rather it is a device to allow for movements in the nominal interest rate. If there were consumption or labor income taxes, the Friedman rule would again be optimal.
} 
result, labor does not move, wages do not move, and therefore nominal predetermined funds are ex-post optimal.

\subsubsection{Optimal steady-state policy}

In order to show that, when $g=0$, the Friedman rule is optimal in the steady state, we first show that steady-state bankruptcy rates are independent of monetary policy.

The following steady state conditions determine $R^{d}, v, z, \bar{\omega}$, and $R^{l}$, for given gross inflation $\Pi$, which is determined by policy:

$$
\begin{gathered}
\frac{1}{\beta}=\frac{R^{d}}{\Pi} \\
v f(\bar{\omega})=\frac{R^{d}}{1-\mu \frac{\bar{\omega} \phi(\bar{\omega})}{1-\Phi(\bar{\omega})}} z \\
v g(\bar{\omega})=R^{d}(1-z) \\
\Pi=(1-\gamma) f(\bar{\omega}) \frac{v}{z} \\
\bar{\omega}=\frac{R^{l}(1-z)}{v} .
\end{gathered}
$$

The first condition is the Euler equation, (5), in the steady state. The second and third conditions are the steady state conditions of the contract, (18) and (19). The fourth condition is the condition for the accumulation of internal funds in the steady state, (22), meaning that the growth rate of internal funds has to be equal to inflation in order for real internal funds to remain constant. Finally, the last condition is the definition of the bankruptcy threshold, (17), in the steady state.

From these conditions, it is clear that higher average inflation in this economy is transmitted one-to-one to the deposit rate, and also to the lending rate. The mark up, $v$, increases, also in the same proportion, because of the intratemporal distortion created by the higher opportunity cost of funds for the firms. Higher average inflation does not affect the conditions of the contract so that the bankruptcy rate and the leverage rate are unchanged. Average inflation is neutral as far as those financial variables are concerned.

Using conditions (28)-(31), we can write

$$
\frac{1-\gamma}{\beta}=1-\frac{\mu \bar{\omega} \phi(\bar{\omega})}{1-\Phi(\bar{\omega})},
$$

and

$$
\frac{f(\bar{\omega})}{g(\bar{\omega})}=\frac{\frac{z}{1-z}}{1-\mu \frac{\bar{\omega} \phi(\bar{\omega})}{1-\Phi(\bar{\omega})}}
$$


that determine $\bar{\omega}$ and $z$, independently of average inflation, and

$$
\Pi=(1-\gamma) f(\bar{\omega}) \frac{\frac{A u_{c}}{\alpha}}{z}
$$

that determines $c$, given $\Pi$. In the $\log$ case, an increase in $\Pi$ leaves $\bar{\omega}$ and $z$ unchanged and lowers consumption and labor in the same proportion.

The equilibrium restrictions in the steady state can be simplified to the implementability condition

$$
\frac{u_{c} A}{\alpha}=\frac{R^{d}}{1-\mu G(\bar{\omega})-f(\bar{\omega}) \frac{\mu \bar{\omega} \phi(\bar{\omega})}{1-\Phi(\bar{\omega})}},
$$

the condition that $\bar{\omega}$ does not depend on policy, (33), and the resource constraint,

$$
(1-g) A N[1-\mu G(\bar{\omega})]=c,
$$

together with the implicit restriction that the nominal interest rate cannot be negative, $R^{d} \geq 1$. The objective is to maximize steady-state utility $u(c)-\alpha n$, subject to those restrictions.

We consider first the case where $g=0$. For an exogenous $\bar{\omega}$, which by (33) is independent of policy, suppose we were to maximize utility, subject to the steady-state resource constraint (36) only. Then, optimality would require that

$$
\frac{u_{c} A}{\alpha}=\frac{1}{1-\mu G(\bar{\omega})} .
$$

From (35), this could only be satisfied if either $\mu=0$ or $\bar{\omega}=0$, and $R^{d}=1$. When credit frictions are present, and $f(\bar{\omega}) \frac{\mu \bar{\omega} \phi(\bar{\omega})}{1-\Phi(\bar{\omega})} \neq 0$, there is a reason to subsidize consumption, which in this economy can only be done by reducing the nominal interest rate. Since $R^{d} \geq 1$, it is optimal to set $R^{d}=1$, as a corner solution. The Friedman rule is optimal.

How can we interpret the optimal subsidy? The subsidy is a second best response to the restriction on the accumulation of internal funds. If $z=1$, there would be no need for external financing and

$$
\bar{\omega}=\frac{R^{l}(1-z)}{v}=0
$$

Since

$$
\frac{u_{c} A}{\alpha}=\frac{R^{d}}{1-\mu G(\bar{\omega})-\mu f(\bar{\omega}) \frac{\bar{\omega} \phi(\bar{\omega})}{1-\Phi(\bar{\omega})}}=R^{d},
$$

then

$$
R^{d}=R^{l}=1
$$


would be exactly optimal, and there would be no reason to subsidize. The scarcity of internal funds is a second best restriction that justifies the subsidy to production.

With $g$ sufficiently greater than zero it is optimal to tax on average. The same argument as above cannot go through. The optimal condition just using the resource constraint would require that

$$
\frac{u_{c} A}{\alpha}=\frac{1}{(1-g)[1-\mu G(\bar{\omega})]} .
$$

In spite of the reason to subsidize, due to $f\left(\bar{\omega}_{t}\right) \frac{\mu \bar{\omega} \phi(\bar{\omega})}{1-\Phi(\bar{\omega})}$, if $g$ is high enough, it is optimal to tax. Then, as we show in the simulations below, it will be optimal to tax at different rates, in response to shocks.

\subsubsection{Optimal cyclical policy}

When $g=0$, in the calibrated version we analyze below, the Friedman rule is optimal also in response to shocks. From condition (27), at the lower bound, we obtain

$$
E_{t-1}\left[\frac{u_{c}(t) A_{t}}{\alpha}\left[1-\mu_{t} G\left(\bar{\omega}_{t}\right)-f\left(\bar{\omega}_{t}\right) \frac{E_{t-1}\left[\mu_{t} \bar{\omega}_{t} \phi\left(\bar{\omega}_{t}\right)\right]}{E_{t-1}\left[1-\Phi\left(\bar{\omega}_{t}\right)\right]}\right]\right]=1
$$

This condition provides some intuition on what is at stake for optimal policy. $\frac{u_{c}(t) A_{t}}{\alpha}$ is the wedge between the marginal rate of substitution and the marginal rate of transformation if the financial technology is not taken into account. The term $\frac{1}{1-\mu_{t} G\left(\bar{\omega}_{t}\right)-f\left(\bar{\omega}_{t}\right) \frac{E_{t-1}\left[\mu_{t} \bar{\omega}_{t} \phi\left(\bar{\omega}_{t}\right)\right]}{E_{t-1}\left[1-\Phi\left(\bar{\omega}_{t}\right)\right]}}$ is the financial markup present in models with costly state verification. The wedge has to be equal to the financial markup, on average, but not always in response to shocks.

One of the frictions in this economy is the predetermination of funds, which is a nominal rigidity. If this was the single friction, meaning that $\mu_{t}=0$, and the nominal interest rate was zero, then condition (38) would be written as

$$
E_{t-1}\left[\frac{u_{c}(t) A_{t}}{\alpha}\right]=1
$$

The reason why this equilibrium condition is in expectation is precisely because of the predetermination of nominal assets. In this case the goal of policy would be to move the price level so that the mark up $\frac{u_{c}(t) A_{t}}{\alpha}$ would be exactly equal to one. Policy would be able to eliminate the single friction in the economy, neutralizing the nominal rigidity. ${ }^{12}$

\footnotetext{
${ }^{12}$ We expand on this in Section 4.
} 
The nominal rigidity associated with the predetermination of nominal assets can be eliminated, as well as the distortion associated with a positive nominal interest rate due to the restriction that wages must be paid before firms receive production. The financial friction associated with the costly state verification cannot be fully eliminated. This economy is in a second or third best, where all these frictions interact. ${ }^{13}$ The financial distortion would justify subsidizing production which, given the zero bound on interest rates, is not possible. In response to shocks, specifically to shocks to technology, it may be optimal to neutralize the friction due to the predetermination of nominal assets, and to stabilize bankruptcy rates. In response to financial shocks, that is no longer the objective of policy.

As the numerical results will show, for logarithmic preferences, the optimal policy in response to technology shocks is to fully stabilize the financial markup, therefore keeping bankruptcy rates constant, and setting the wedge equal to the constant financial markup. Given that utility is logarithmic, consumption is proportional to the technology shock, which implies that labor does not move. From (11), we have that $X_{t-1}=\frac{P_{t} A_{t}}{v_{t}} N_{t}$. Since $N_{t}=N$, $v_{t}=v$, and $X_{t-1}$ does not vary with shocks in $t$, it must be that the price level is inversely proportional to the technology shock. Since nominal funds are predetermined and labor does not move, the optimal policy is to keep the nominal wage constant and adjust the price level to the movements in the real wage.

\section{Numerical results}

The model calibration is very standard. We assume utility to be logarithmic in consumption and linear in leisure. Following Carlstrom and Fuerst (1997), we calibrate the volatility of idiosyncratic productivity shocks and the steady state death probability $\gamma$, so as to generate an annual steady state credit spread of approximately $2 \%$ and a quarterly bankruptcy rate of approximately $1 \% .^{14}$ The monitoring cost parameter $\mu$ is set at 0.15 following Levin et al. (2004).

In the rest of this section, we always focus on adverse shocks, i.e. shocks which tend to generate a fall in output. Impulse responses under optimal policy refer to an equilibrium in which policy is described by the first order conditions of a Ramsey planner deciding allocations for all times $t \geq 1$, but ignoring the special nature of the initial period $t=0$. Responses under

\footnotetext{
${ }^{13}$ The restriction that government spending is a share of production can also be seen as another distortion.

${ }^{14}$ The exact values are $1.8 \%$ for the annual spread and $1.1 \%$ for the bankruptcy rate.
} 
a Taylor rule refer to an equilibrium in which policy is set according to the following simple interest rate rule:

$$
\widehat{r}_{t}^{d}=1.5 \cdot \widehat{\pi}_{t}
$$

where $r_{t}^{d} \equiv \ln R_{t}^{d}, \pi_{t} \equiv \ln \left(P_{t} / P_{t-1}\right)$ and hats denote logarithmic deviations from the nonstochastic steady state.

In all cases, we only study the log-linear dynamics of the model.

\subsection{Impulse responses under optimal policy}

Optimal policy in the calibrated version of the model entails setting the nominal interest rate permanently to zero, as long as $g=0$. This restriction is imposed when computing impulse responses.

\subsubsection{Technology shocks}

Figure 1 shows the impulse response of selected macroeconomic variables to a negative, 1\% technology shock under optimal policy. The variables are the technology process $a_{t} \equiv \ln A_{t}$, output $y_{t} \equiv \ln \left(A_{t} N_{t}\right)$, real internal funds $\bar{z}_{t} \equiv \ln \left(Z_{t-1} / P_{t}\right)$, and inflation $\pi_{t}$. Bankruptcy rates, markups, spreads, and leverage are not represented because there is no effect of the shock on those under the optimal policy.

It is important to recall that the model includes many features which could potentially lead to equilibrium allocations that are far from the first best: asymmetric information and monitoring costs; the predetermination of financial decisions; and the nominal denomination of debt contracts. At the same time, the presence of nominal predetermined contracts implies that monetary policy is capable of affecting allocations by choosing appropriate sequences of prices.

Figure 1 illustrates that optimal policy is able to replicate the first-best response of consumption and labor allocations to a technology shock. ${ }^{15}$ In response to the negative technology shock, since nominal internal and external funds are predetermined, optimal policy generates inflation for 1 period. As a result, the real value of total funds needed to finance production falls exactly by the amount necessary to generate the correct reduction in output.

In subsequent periods, the real value of total funds is slowly increased through a mild reduction in the price level. Along the adjustment path, leverage remains constant and firms

\footnotetext{
${ }^{15}$ The allocations are distorted, but the responses are as in the first best.
} 
make no losses. Consumption moves one-to-one with technology, while hours worked remain constant. With constant labor and an equilibrium nominal wage that stays constant, the restriction that funds are predetermined is not relevant. The price level adjusts so that the real wage is always equal to productivity. Since total funds are always at the desired level, the accumulation equation for nominal funds never kicks in. 
Figure 1: Impulse responses to a negative technology shock under optimal policy
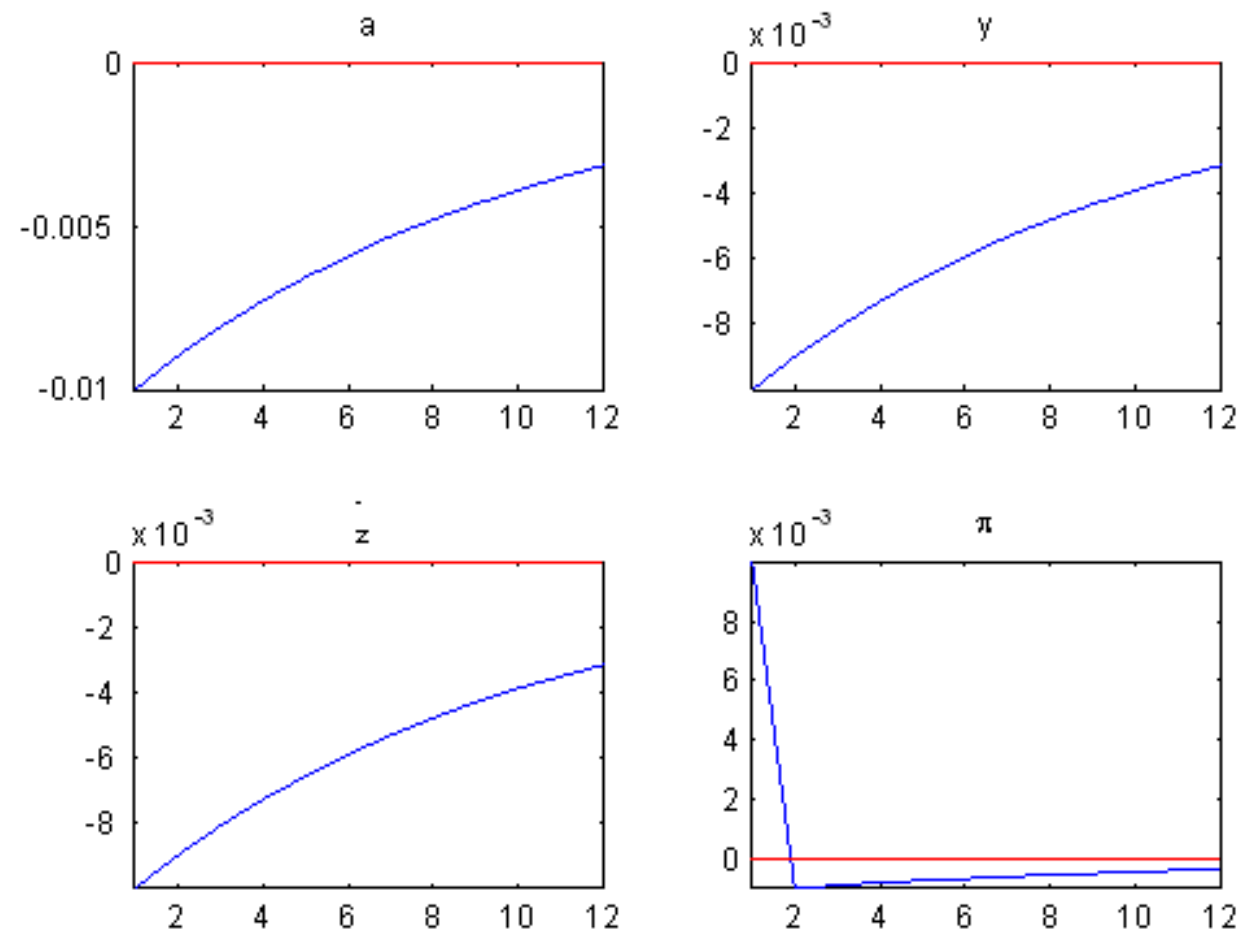

Note: Logarithmic deviations from the non-stochastic steady state. Correlation of the shock: 0.9 .

The impulse responses in Figure 1 would obviously be symmetric after a positive technology shock. Hence, perfect inflation stabilization - i.e. an equilibrium in which inflation is kept perfectly constant at all points in time - is not optimal (we show below that this is the case for all shocks, not just technology shocks). Allowing for short-term inflation volatility is useful to help firms adjust their funds, both internal and external, to their production needs. In the case of technology shocks, this policy also prevents any undesirable fluctuations in the economy's bankruptcy rate, financial markup, or the markup resulting from the predetermination of assets.

This result is robust to a number of perturbations of the model. It also holds if there are reasons not to keep the nominal interest rate at zero. And it holds in a model where internal and external funds are perfect substitutes. 


\subsubsection{Financial shocks}

We can analyze the impulse responses to three types of financial shocks. The first is an increase in $\gamma_{t}$, namely a shock which generates an exogenous reduction in the level of internal funds. The second one is a shock to the standard deviation of idiosyncratic technology shocks, $\sigma_{\omega_{i, t}}$, which amounts to an increase in the uncertainty of the economic environment. The third shock is an increase in the monitoring cost parameter $\mu_{t}$. In the text, we focus on the first shock. The other two shocks are analyzed in Appendix 3.

Contrary to the case of Figure 1, bankruptcy rates, markups, spreads, and leverage are not constant after financial shocks. In all these cases, therefore, we also report impulse responses of: $z_{t} \equiv \ln \left(Z_{t} / X_{t}\right)$; (log-)consumption, $c_{t}$; the share of firms that go bankrupt, $\Phi\left(\bar{\omega}_{t}\right)$; the (log-)markup, $v_{t}$; the spread between the lending and the deposit rate, $\Delta_{t} \equiv \ln \left(R_{t}^{l} / R_{t}^{d}\right)$.

The impulse responses to $\gamma_{t}$ in Figure 2 are interesting because they generate at the same time a reduction in output and an increase in leverage. Leverage can be defined as the ratio of external to internal funds used in production, i.e. as $1 / z_{t}-1$ and it is therefore negatively related to $z_{t}$. To highlight the different persistence of the effects of the shock, depending on the prevailing policy rule, we focus on a serially uncorrelated shock.

The higher $\gamma$ does not have an effect on funds on impact because of the predetermination of financing decisions, but it represents a fall in internal funds at $t+1$, which leads to an increase in firms' leverage. 
Figure 2: Impulse responses to a fall in the value of internal funds under optimal policy
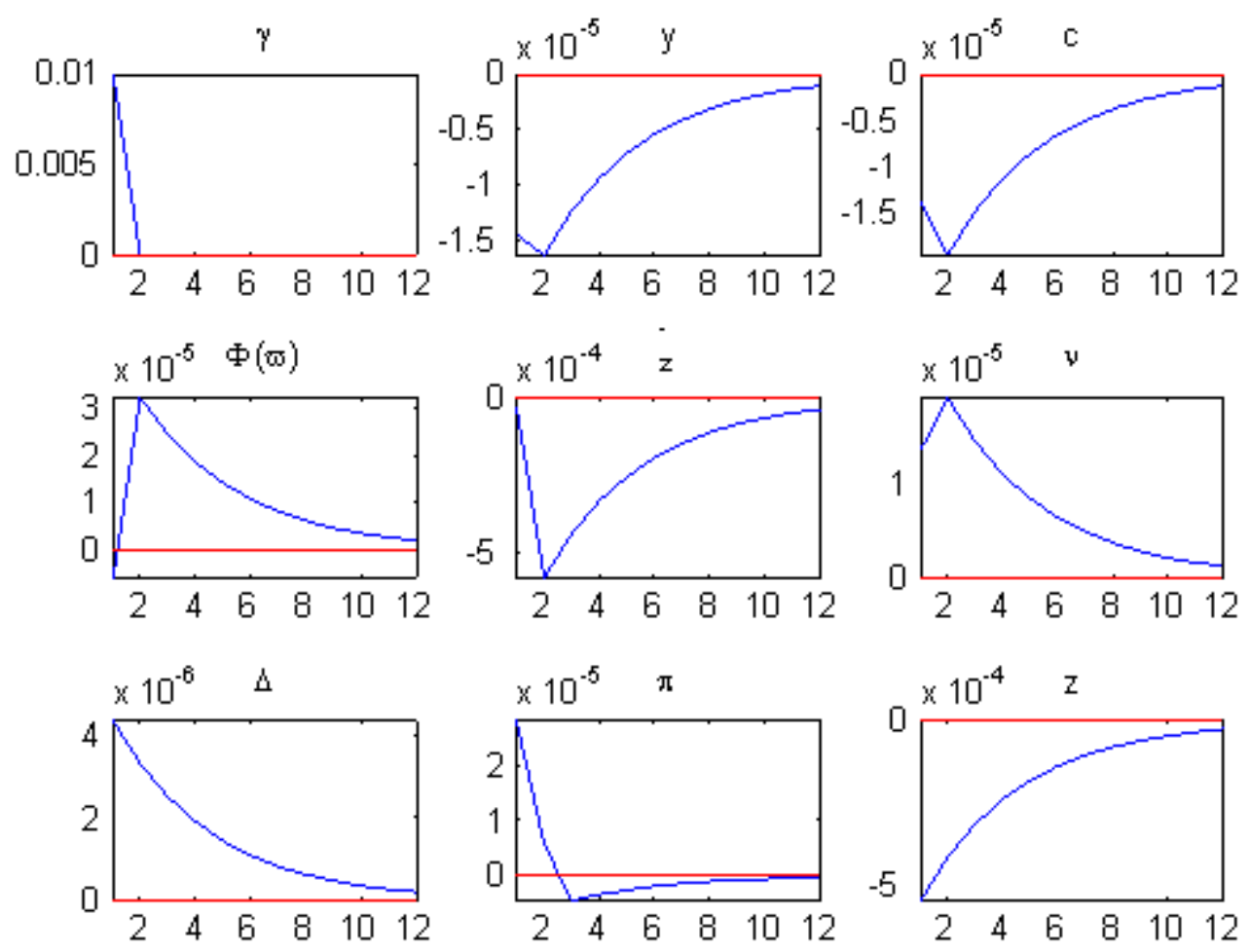

Note: Logarithmic deviations from the non-stochastic steady state. Serially uncorrelated shock.

We will see below that under a Taylor rule this shock brings about a period of deflation, which would be quite persistent if the original shock were also persistent. The optimal policy response, instead, is to create a short-lived period of inflation. The impact increase in the price level lowers the real value of total funds, so as to decrease labor and production levels. Mark ups increase on impact, as output and consumption decrease, so that the future cut in internal funds can be partially offset. The higher profits allow firms to quickly start rebuilding their internal funds. The adjustment process is essentially complete after 3 years. When consumption starts growing towards the steady state, the real rate must increase. For given nominal interest rate, there must be a period of mild deflation.

\subsection{Optimal policy when a non-zero interest rate is optimal}

In this section, we explore to which extent the optimal policy recommendations described above are affected by the fact that the nominal interest rate is kept constant at zero. In 
the calibration, we keep all other parameters unchanged, but we assume that there is a fixed share of government consumption $g>0$. As discussed above, the optimal steady state level of the nominal interest rate increases proportionately. We therefore calibrate the government consumption share to generate a reasonably small steady state value of the nominal interest rate, namely $g=0.02 .^{16}$

\subsubsection{Technology shocks}

In spite of the availability of the nominal interest rate as a policy instrument, the optimal response to a technology shock is the same as before. Policy replicates the response of the allocations which would be attained in a frictionless model, whether nominal interest rates can be moved or not. This result is striking, because it implies that, in reaction to technology shocks, the zero bound on nominal interest rates does not represent a constraint for monetary policy in our model.

The result, however, holds solely in reaction to technology shocks. As discussed next, the zero bound does represent a constraint for monetary policy in response to financial shocks.

\subsubsection{Financial shocks}

For all financial shocks, the flexibility of using the nominal interest rate allows policy to speed up the adjustment after financial shocks. The effect of these shocks on output is considerably mitigated. We illustrate this general result with a serially uncorrelated shock to $\gamma$.

The impulse responses to this shock under the optimal policy are shown in Figure 3, together with the impulse responses in the case where the Friedman rule is optimal. The most striking result is that the impact of this shock on output, which is persistently contractionary when the short term nominal rate is kept fixed at zero, is less contractionary and very short-lived when the interest rate can be reduced.

The reduction in policy rates improves credit conditions directly, because it also reduces loan rates - the increase in the credit spread is largely comparable to the case when the Friedman rule is optimal. After decreasing on impact, output can immediately return to the steady state, while consumption has to adjust at a lower pace because of the increase in aggregate monitoring costs. The mildly positive rate of growth of consumption along the

\footnotetext{
${ }^{16}$ Compared to the $g=0$ case, there is an increase in the steady state level of the credit spread, to $1.27 \%$, and of the bankruptcy rate, to $6.7 \%$.
} 
adjustment path implies that the real interest rate must also be positive. Given the protracted fall in the policy interest rate, inflation must also fall persistently - and by slightly more than the nominal interest rate - after its impact increase.

Figure 3: Impulse responses to a fall in the value of internal assets under optimal policy
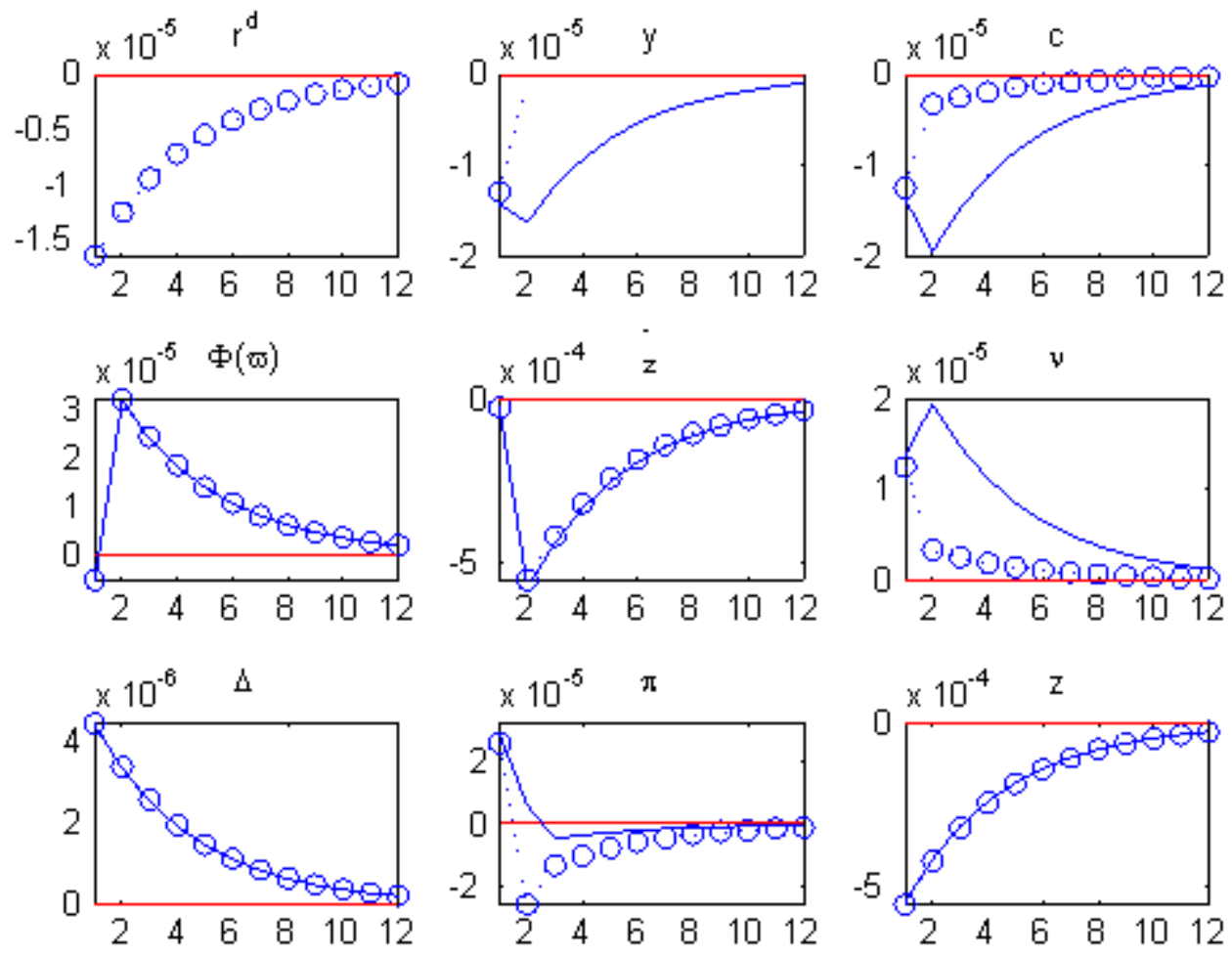

Note: Logarithmic deviations from the non-stochastic steady state. Uncorrelated shock. The lines with circles indicate impulse responses under optimal policy when $g>0$; the solid lines report impulse responses under optimal policy already shown in Figure 2.

The impact effect of the shock on mark-ups is comparable to the case in which the Friedman rule is optimal, but the adjustment process is much faster.

\subsection{Taylor rule policy}

We now compare the impulse responses under optimal policy and $g>0$ with those in which policy follows the simple Taylor rule in equation (40). 


\subsubsection{Technology shocks and the cyclicality of bankruptcies}

In response to a negative technology shock, the simple Taylor rule tries to stabilize inflation (see Figure 4). The large amount of nominal funds that firms carry over from the previous period, therefore, has high real value. Given the available funds, firms hire more labor and the output contraction is relatively small, compared to what would be optimal at the new productivity level. As a result, the wage share increases and firms make lower profits, hence they must sharply reduce their internal funds. Leverage goes up, and so do the credit spread and the bankruptcy rate. In the period after the shock, firms start accumulating funds again, but accumulation is slow and output keeps falling for a whole year after the shock. It is only in the second year after the shock that the recovery begins.

Figure 4 illustrates how our model is able to generate realistic, cyclical properties for the credit spread and the bankruptcy ratio. An increase in bankruptcies is almost a definition of recession in the general perception, while the fact that credit spreads are higher during NBER recession dates is documented, for example, in Levin et al. (2004). Generating the correct cyclical relationship between credit spreads, bankruptcies and output is not straightforward in models with financial frictions. For example, spreads are unrealistically procyclical in the Carlstrom and Fuerst $(1997,2000)$ framework. The reason is that firms' financing decisions are state contingent in those papers. Firms can choose how much to borrow from the banks after observing aggregate shocks. Should a negative technology shock occur, they would immediately borrow less and try to cut production. This would avoid large drops in their profits and internal funds, so that their leverage would not increase. As a result, bankruptcy rates and credit spreads could remain constant or decrease during the recession.

In our model, economic outcomes are reversed because of the pre-determination in financial decisions. Firms' loans are no-longer state contingent, hence they cannot be changed after observing aggregate shocks. This assumption implies that firms are constrained in their impact response to disturbances. After a negative technology shock, firms find themselves with excessive funds and their profits fall because production levels do not fall enough. The reverse would happen during an expansionary shock, when production would initially increase too little and profits would be high. 
Figure 4: Impulse responses to a negative technology shock under a Taylor rule
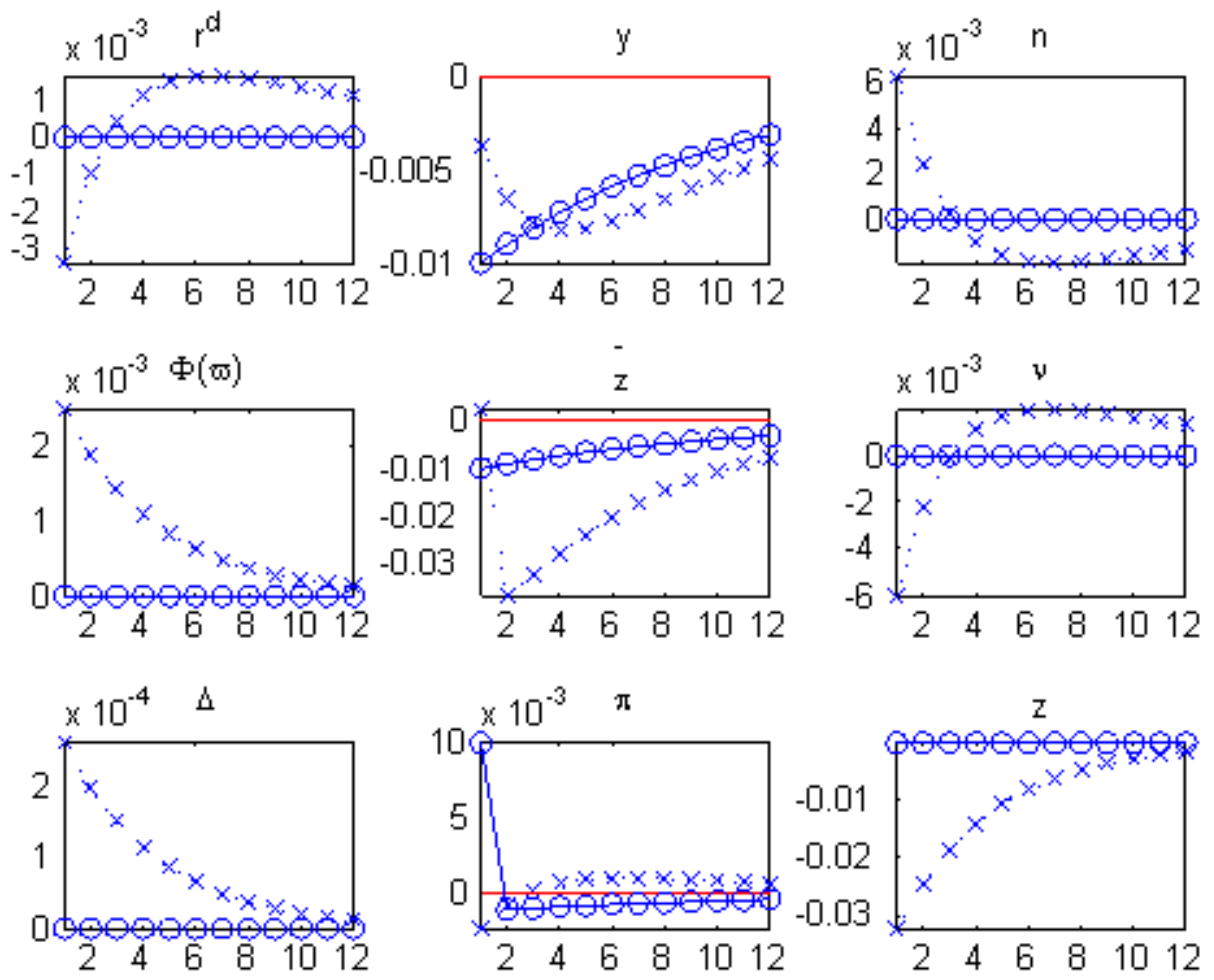

Note: Logarithmic deviations from the non-stochastic steady state. Correlation of the shock: 0.9. The lines with crosses indicate impulse responses under the Taylor rule; the lines with circles report the impulse responses under optimal policy already shown in Figure 1.

The model also generates a realistically hump-shaped impulse response of output and consumption without the need for additional assumptions, such as habit persistence in households' preferences. Once a shock creates the need for changes in internal funds, these changes can only take place slowly. Compared to the habit persistence assumption, our model implies that the hump-shape in impulse responses is policy-dependent. After a technology shock, optimal policy keeps internal funds at their optimal level at any point in time. Firms do not need to accumulate, or decumulate, internal funds, and, as a result, the hump in the response of output and consumption disappears.

A notable feature of Figure 4 is that the Taylor rule generates the "wrong" reaction of prices to the negative technology shock compared to optimal policy - a small deflation on impact, rather than inflation. The reason is related to the hump-shaped response of consumption, which implies that the real interest rate must fall for a few quarters after the shock. If inflation 
increased on impact, the policy rate would have to increase by less than inflation in order to bring about a negative real interest rate. However, this policy response would be inconsistent with the rule in equation (40), which requires the interest rate to increase more than inflation. The fall in the real interest rate must therefore be implemented through a reduction in the nominal interest rate and a period of deflation.

This result is independent of the size of the inflation response coefficient in the Taylor rule - provided that the rule is consistent with a determinate equilibrium. If the inflation response coefficient were higher (lower), deflation would simply be smaller (larger). Only in the limiting case of a very large response coefficient would the outcome be not deflation, but a situation very close to price stability.

An implication of this result is that, after a technology shock, the higher the inflation response coefficient in the Taylor rule, the closer is the Taylor rule to optimal policy. Intuitively, price stability is closer to the inflationary outcome produced by optimal policy than the deflation rate generated by the Taylor rule. This property of the Taylor rule in our model is reminiscent of the results in Gilchrist and Leahy (2002) and Faia and Monacelli (2007), where a Taylor rule with a high inflation response coefficient delivers superior outcomes. The overall properties of the Taylor rule, however, are very different. Gilchrist and Leahy (2002) and Faia and Monacelli (2007) also assume sticky prices, and price stability is optimal in that environment. In our model, allocations under price stability would remain far away from the optimum. After a negative technology shock, the real level of funds would still be too high, so that production and consumption would come down in a hump-shape manner, rather than on impact as they should.

\subsubsection{Shocks to the value of internal assets}

A reduction in the value of internal assets leads to an increase in leverage, the economy's bankruptcy rate and credit spreads (see Figure 5). As in the case of optimal policy (when $g>0$ ), the Taylor rule prescribes a fall in the policy interest rate. For similar reasons to those applying in the case of technology shocks, however, the Taylor rule brings about deflation, rather than inflation. Deflation keeps output too high on impact and generates a fall in markups. As a result, the impact increase in leverage is more pronounced than under optimal policy. Consequently, the de-leveraging process is very slow and consumption is still away from the steady state three years after the shock. Compared to the optimal policy case, the recession 
is more persistent and it comes at the cost of a higher bankruptcy rate and a higher credit spread.

Figure 5: Impulse responses to a fall in the value of internal assets under a Taylor rule
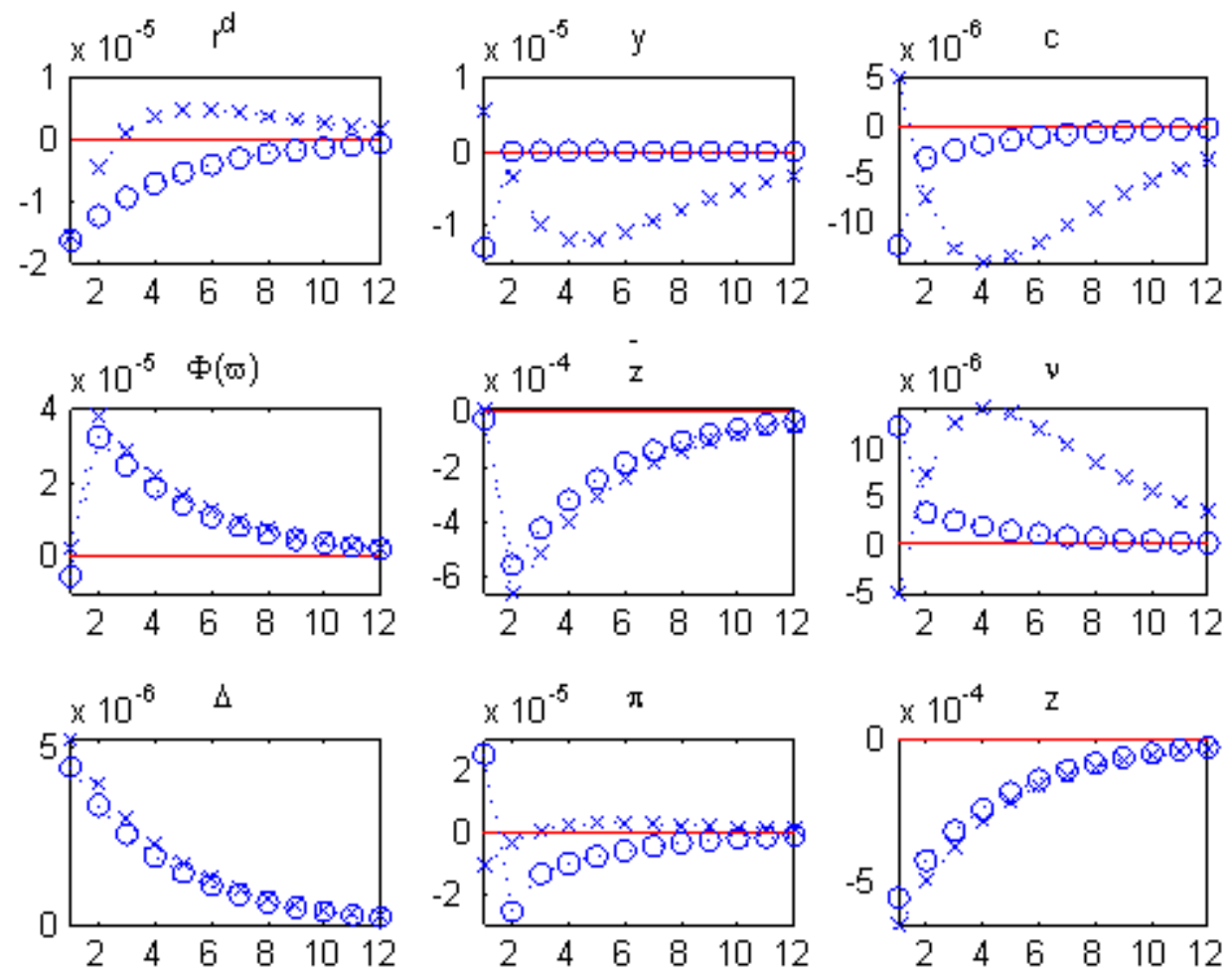

Note: Logarithmic deviations from the non-stochastic steady state. The shock is serially uncorrelated. The lines with crosses indicate impulse responses under the Taylor rule; the lines with circles report the impulse responses under optimal policy already shown in Figure 3.

Under a Taylor rule, this shock leads to a situation akin to the "initial state of overindebtedness" described in Fisher (1933), in which firms' leverage increase and deflation ensues. In Fisher's theory, firms try to de-leverage through a fast debt liquidation and the selling tends to drive down prices. If monetary policy accommodates this trend, the price level also falls and the real value of firms liabilities increase further, leading to even higher leverage and further selling. In our model, over-indebtedness and leverage are also exacerbated by deflation, but the mechanics of the model are different. De-leveraging occurs through an accumulation of assets, rather than a liquidation of debt. 


\subsubsection{Policy shocks}

Figure 6 shows the impulse responses to a serially correlated shock to the Taylor rule, corresponding to an increase in the policy rate.

The shock is useful to illustrate the general features of the monetary policy transmission mechanism in this model. These are characterized by the slow accumulation of internal funds, which produces very persistent responses in all variables.

Figure 6: Impulse responses to a monetary policy shock
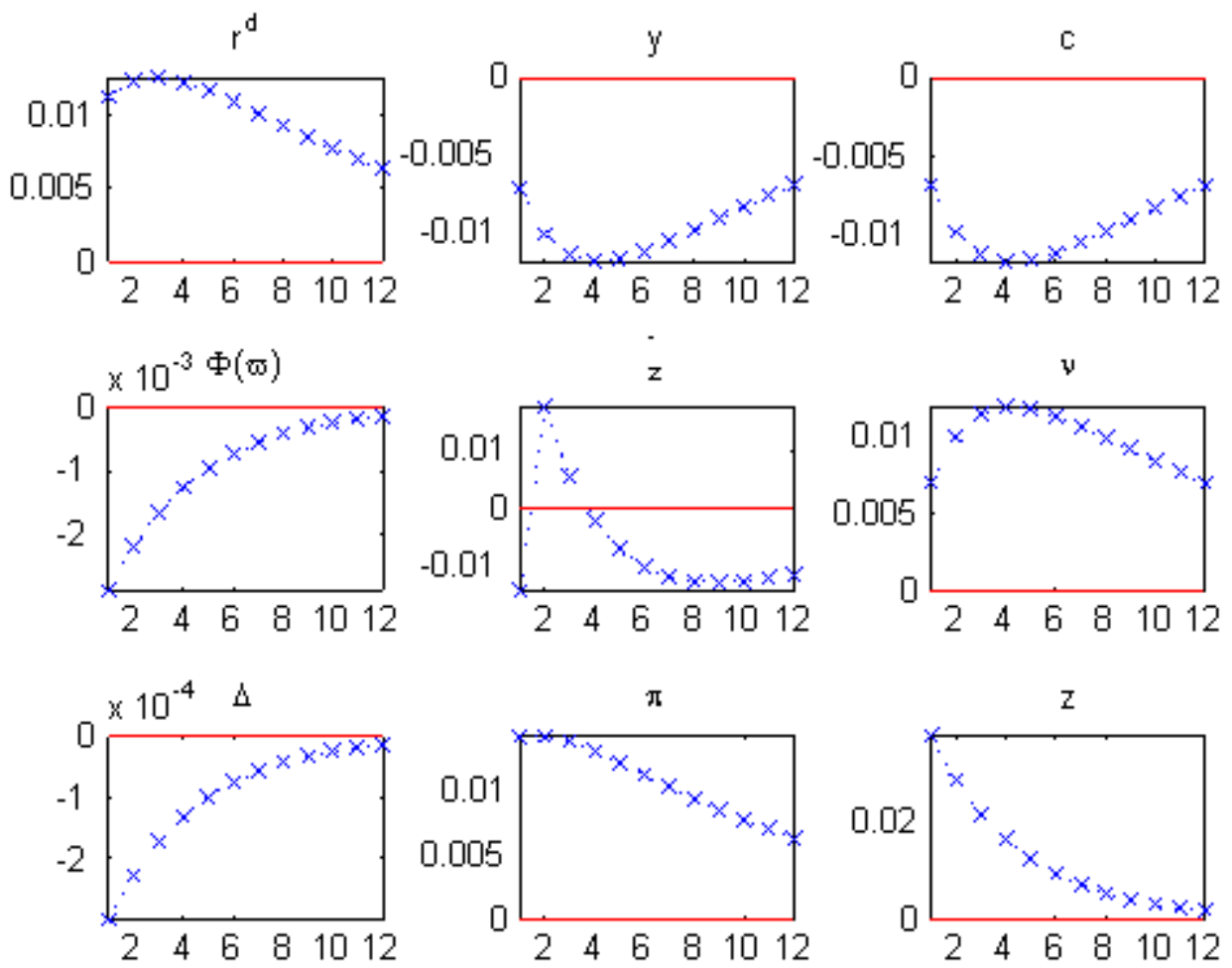

Note: Logarithmic deviations from the non-stochastic steady state. Correlation of the shock: 0.9 .

The shock generates an immediate increase in the price level which reduces the real value of firms' nominal funds and induces a contraction in production and consumption through a fall in employment and real wages. Since leverage is predetermined in the first period, the lower production level brings about a reduction in the bankruptcy rate. Profits increase and, after one period, firms find themselves with an excess of internal funds. They therefore start 
decumulating them, but the adjustment process is very slow. Three years after the shock, output, consumption and employment are still far away from the steady state.

\section{The case in which internal and external funds are perfect substitutes}

In order to better understand the results of the general model, we analyze a simplified case in which assets are predetermined, but internal and external funds are perfect substitutes - i.e. monitoring costs are zero.

Even in the absence of costly state verification, it is not optimal to stabilize inflation at all times. Hence, the predetermination of assets and the nominal denomination of funds are responsible for the deviation from price stability under the optimal policy in the general model.

We also use this model to evaluate the role played by asymmetric information and monitoring costs in explaining business cycle fluctuations. We find that, although these imperfections play a quantitatively minor role in determining the cyclical behavior of non-financial variables, they tend to amplify the reaction of the economy to shocks.

\subsection{Inflation stabilization is not optimal}

We consider the case where $g>0$, and the nominal interest rate is high enough that the borrowing constraint of firms is always binding. In the model with financial frictions this was not necessary since positive financial markups guaranteed that the constraint was binding.

The equilibrium conditions in this economy are given by (3)-(6), together with

$$
\begin{gathered}
R_{t-1}^{l}=R_{t-1}^{d} \equiv R_{t-1}, t \geq 1 \\
E_{t-1}\left[v_{t}\right]=R_{t-1}, t \geq 1 \\
N_{t}=\frac{X_{t-1}}{W_{t}}, t \geq 0 \\
v_{t}=\frac{A_{t} P_{t}}{W_{t}}, t \geq 0 \\
c_{t}=(1-g) A_{t} N_{t}, t \geq 0 .
\end{gathered}
$$

where $R_{t}$ is the policy rate. 
The implementability conditions restricting $c_{t}, N_{t}, t \geq 0$, and $R_{t-1}, t \geq 1$, are:

$$
\begin{gathered}
E_{t-1}\left[\frac{u_{c}(t) A_{t}}{\alpha}\right]=R_{t-1}, t \geq 1 \\
c_{t}=(1-g) A_{t} N_{t}, t \geq 0
\end{gathered}
$$

Every equilibrium sequence for $c_{t}, N_{t}, t \geq 0$, and $R_{t-1}, t \geq 1$, in this set can be implemented. The other equilibrium conditions are satisfied by the choice of the remaining variables: (41) determine $R_{t-1}^{l}$ and $R_{t-1}^{d}, t \geq 1$. For $t=0$, given a value $X_{-1}$ and an allocation $c_{0}$ and $N_{0}$, (42) and (3) are satisfied by the choice of $W_{0}$ and $P_{0}$. For $t \geq 1$, given an allocation $c_{t}$ and $N_{t}$, and $R_{t-1}$, conditions (3), (5) and (42) are satisfied by the choice of $W_{t}, P_{t}$ and $X_{t-1}$. There are two contemporaneous conditions and one predetermined condition for two contemporaneous variables and one predetermined variable. (43) determines $v_{t}$; (4) determines $Q_{t-1, t}^{-1}$, and (6) restricts $m_{t}$.

The restriction that government consumption is a constant share of production is a secondbest restriction in this environment, implying the optimal use of proportionate taxation, even if lump-sum taxation is available. The optimal, second-best, allocation maximizes utility subject to the resource constraints

$$
c_{t} \leq(1-g) A_{t} N_{t}
$$

Optimality requires that

$$
\frac{u_{c}(t)}{\alpha}=\frac{1}{(1-g) A_{t}}, t \geq 0 .
$$

This optimal allocation can be implemented in this economy with predetermined assets, since it satisfies the implementability condition (45) when the interest rate is

$$
R_{t-1}=\frac{1}{1-g}, t \geq 1
$$

In this economy, monetary policy does much more than just setting the interest rate. Implementing the optimal allocation, requires moving the price level to adjust the real value of funds.

Under log-linear preferences, labor would not move in response to shocks to productivity, $A_{t}$. Since funds are predetermined, in (42), the wage rate could not move either and, from (3), the price level would have to be inversely proportional to consumption, or to the shocks to productivity. 


\subsection{The role of asymmetric information and monitoring costs}

Figure 7 compares the reaction to a technology shock under the Taylor rule in the general model of section 2 and in the model of this section. The figure shows that the differences between the two cases are not overwhelming, but the model with asymmetric information and monitoring costs tends to amplify business cycle fluctuations in response to shocks. Compared to the simpler model, the recession induced by a negative technology shock is deeper when accompanied by an increase in credit spreads and in the bankruptcy rate. Employment fluctuations are also more pronounced and so is the volatility of inflation and of the policy interest rate. 
Figure 7: Impulse responses to a negative techology shock under a Taylor rule
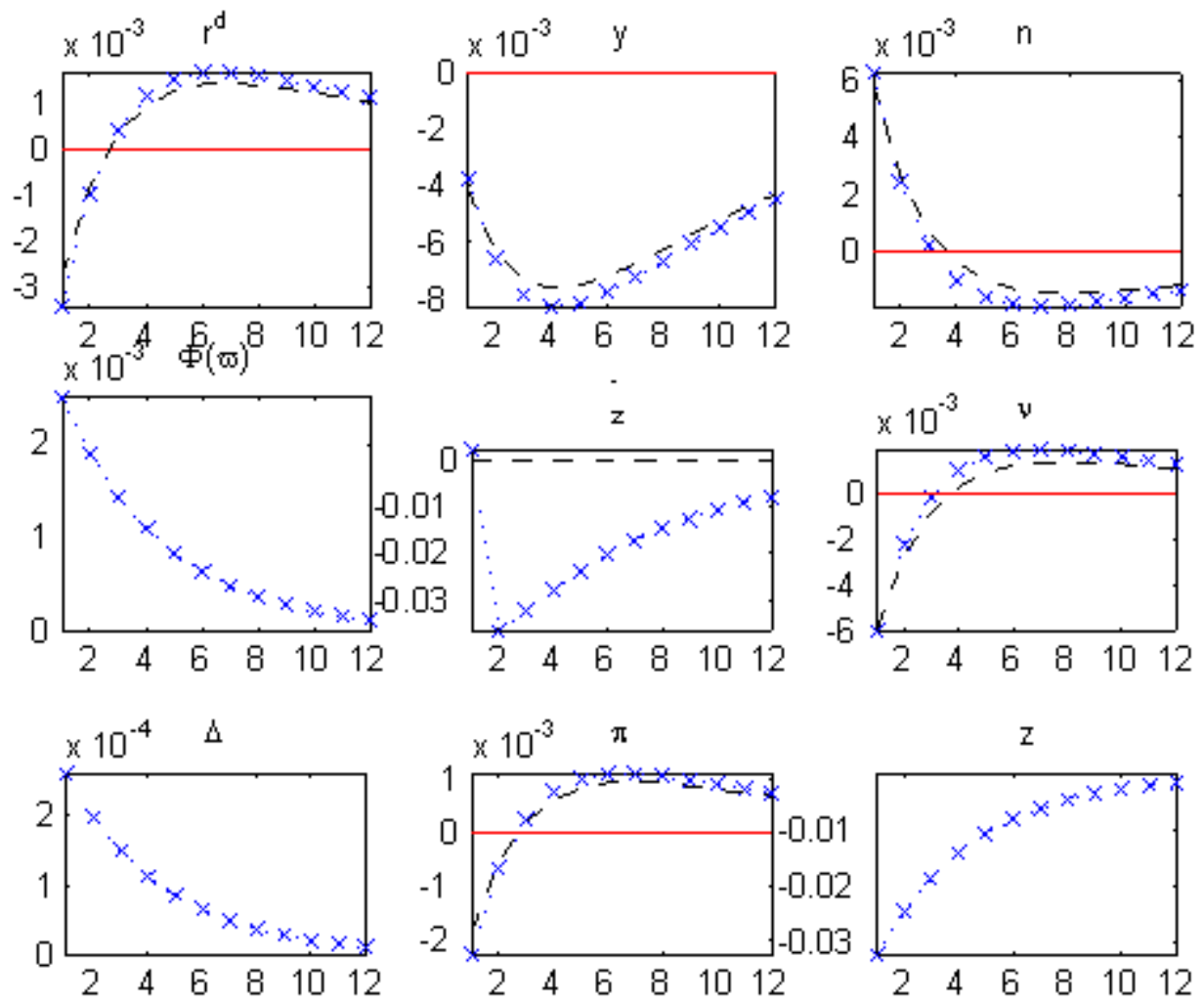

Note: Logarithmic deviations from the non-stochastic steady state. Correlation of the shock: 0.9. The dashed lines report the impulse responses in the case where internal and external funds are perfect substitutes; the lines with crosses corresponds to those in Figure 4.

\section{Conclusions}

The model described in this paper represents an attempt to clarify the policy incentives created by the nominal denomination of firms' debt. Our analysis is based on a number of simplifying assumptions and does not aim to provide quantitative policy prescriptions. Nevertheless, we highlight results that may be of relevance also in more general frameworks.

The first result is that maintaining price stability at all times is not optimal when firms financial positions are denominated in nominal terms and debt contracts are not state-contingent. After a negative technology shock, for example, an impact increase in the price level stabilizes firms' leverage and allows for a more efficient economic response to the shock. This ability of 
monetary policy to influence the real value of firms' assets and liabilities derives from the assumption that, when shocks occur, financial contracts are predetermined. The policy response through the price level is such that, in response to technology shocks, there is no need for the central bank to adjust the nominal interest rate.

A second result is that the optimal response to an exogenous reduction in internal funds, which amounts to an increase in firms' leverage, is to reduce the nominal interest rate, if the nominal rate is not at its zero bound, and to engineer a short period of controlled inflation. Both policy responses have the advantages of mitigating the adverse consequences of the shock on bankruptcy rates and of allowing firms to quickly de-leverage.

Finally, we show that a simple Taylor-type rule would produce significantly different economic outcomes from those prevailing if policy is set optimally. For example, under a Taylor rule bankruptcy rates would increase during recessions, as it appears to be the case in the empirical evidence. Bankruptcy rates would instead be acyclical under optimal policy.

\section{A Appendix}

\section{A.1 The financial contract}

Consider the optimal financial contract problem that maximizes (14) subject to (15) and (16), where $f\left(\bar{\omega}_{i, t}\right)$ and $g\left(\bar{\omega}_{i, t} ; \mu_{t}\right)$ are given by $(9)$ and $(10)$, respectively, and $\bar{\omega}_{i, t}=\frac{R_{i, t-1}^{l}}{\frac{P_{t} A_{t}}{W_{t}}}\left(1-\frac{Z_{i, t-1}}{X_{i, t-1}}\right)$.

The solution for $\frac{Z_{i, t-1}}{X_{i, t-1}}, R_{i, t-1}^{l}$, and $\bar{\omega}_{i, t}$ is the same across firms. Let $z_{t-1} \equiv \frac{Z_{i, t-1}}{X_{i, t-1}}$ and $v_{t} \equiv \frac{P_{t} A_{t}}{W_{t}}$. We can define the function $\bar{\omega}_{i, t} \equiv \bar{\omega}_{t}=\bar{\omega}\left(R_{t-1}^{l}, z_{t-1} ; v_{t}\right)$ as

$$
\bar{\omega}_{t}=\frac{R_{t-1}^{l}\left(1-z_{t-1}\right)}{v_{t}} .
$$

We can rewrite the problem as

$$
\max E_{t-1}\left[v_{t} \frac{1}{z_{t-1}} f\left(\bar{\omega}\left(R_{t-1}^{l}, z_{t-1} ; v_{t}\right)\right)\right]
$$

subject to

$$
\begin{aligned}
E_{t-1}\left[v_{t} g\left(\bar{\omega}\left(R_{t-1}^{l}, z_{t-1} ; v_{t}\right) ; \mu_{t}\right)\right] & \geq R_{t-1}^{d}\left(1-z_{t-1}\right) \\
E_{t-1} v_{t} f\left(\bar{\omega}\left(R_{t-1}^{l}, z_{t-1} ; v_{t}\right)\right) & \geq R_{t-1}^{d} z_{t-1}
\end{aligned}
$$

where the functions $f\left(\bar{\omega}_{i, t}\right)$ and $g\left(\bar{\omega}_{i, t} ; \mu_{t}\right)$ are given by $(9)$ and (10), respectively. 
Define as $\lambda_{1, t-1}$ and $\lambda_{2, t-1}$ the Lagrangean multipliers of (49) and (50) respectively. Conjecturing that $\lambda_{2, t-1}=0$, the first-order conditions are

$$
\begin{gathered}
0=E_{t-1}\left[-\frac{v_{t}}{z_{t-1}^{2}} f\left(\bar{\omega}\left(R_{t-1}^{l}, z_{t-1} ; v_{t}\right)\right)+\frac{v_{t}}{z_{t-1}} f_{2}\left(R_{t-1}^{l}, z_{t-1} ; v_{t}\right)\right] \\
+\lambda_{1 t-1} E_{t-1}\left[v_{t} g_{2}\left(R_{t-1}^{l}, z_{t-1} ; v_{t}, \mu_{t}\right)+R_{t-1}^{d}\right] \\
E_{t-1}\left[\frac{v_{t}}{z_{t-1}} f_{1}\left(R_{t-1}^{l}, z_{t-1} ; v_{t}\right)\right]+\lambda_{1 t-1} E_{t-1}\left[g_{1}\left(R_{t-1}^{l}, z_{t-1} ; v_{t}, \mu_{t}\right) v_{t}\right]=0 \\
E_{t-1} g\left(\bar{\omega}\left(R_{t-1}^{l}, z_{t-1} ; v_{t}\right) ; \mu_{t}\right) v_{t}=R_{t-1}^{d}\left(1-z_{t-1}\right)
\end{gathered}
$$

where $f_{j}$ and $g_{j}$, with $j=1,2$, are the derivatives of $f$ and $g$ with respect to the first and second argument of the function $\bar{\omega}\left(R_{t-1}^{l}, z_{t-1} ; v_{t}\right)$.

We can rewrite these conditions as

$$
\begin{aligned}
& \lambda_{1 t-1} R_{t-1}^{d} z_{t-1}=E_{t-1}\left[\frac{v_{t}}{z_{t-1}} f\left(\bar{\omega}\left(R_{t-1}^{l}, z_{t-1} ; v_{t}\right)\right)\right], \\
& R_{t-1}^{l}\left(1-z_{t-1}\right) \lambda_{1 t-1} E_{t-1}\left[\frac{\mu_{t}}{v_{t}} \phi\left(\frac{R_{t-1}^{l}\left(1-z_{t-1}\right)}{v_{t}}\right)\right] \\
& +\left(\frac{1}{z_{t-1}}-\lambda_{1 t-1}\right) E_{t-1}\left[1-\Phi\left(\frac{R_{t-1}^{l}\left(1-z_{t-1}\right)}{v_{t}}\right)\right]=0, \\
& E_{t-1}\left[g\left(\bar{\omega}\left(R_{t-1}^{l}, z_{t-1} ; v_{t}\right) ; \mu_{t}\right) v_{t}\right]=R_{t-1}^{d}\left(1-z_{t-1}\right) .
\end{aligned}
$$

From the second condition, since $z_{t-1}<1$ and $\lambda_{1 t-1}>0$, $R_{t-1}^{l}\left(1-z_{t-1}\right) \lambda_{1 t-1} E_{t-1}\left[\frac{\mu_{t}}{v_{t}} \phi\left(\frac{R_{t-1}^{l}\left(1-z_{t-1}\right)}{v_{t}}\right)\right]>0$. Moreover, $1>\Phi\left(\frac{R_{t-1}^{l}\left(1-z_{t-1}\right)}{v_{t}}\right)$ so that $\lambda_{1 t-1}-\frac{1}{z_{t-1}}>0$ and $\lambda_{1 t-1} z_{t-1}>1$. It follows that $R_{t-1}^{d} z_{t-1}<E_{t-1}\left[v_{t} f\left(\bar{\omega}\left(R_{t-1}^{l}, z_{t-1} ; v_{t}\right)\right)\right]$, which verifies the conjecture that $\lambda_{2 t-1}=0$.

Using the definition of the threshold, (48), the first-order conditions can be written as (18) and (19).

\section{A.2 Equilibria}

The equilibrium conditions restricting the variables $\left\{c_{t}, N_{t}, v_{t}, P_{t}, R_{t}^{d}, \bar{\omega}_{t}, z_{t}, R_{t}^{l}, X_{t}, Z_{t}\right\}$ given $z_{-1}, X_{-1}, Z_{-1}=z_{-1} X_{-1}$, and $R_{-1}^{l}$, can be summarized by

$$
\frac{u_{c}(t)}{\alpha}=\frac{v_{t}}{A_{t}}, t \geq 0
$$




$$
\begin{gathered}
\frac{u_{c}(t-1)}{P_{t-1}}=R_{t-1}^{d} \beta E_{t-1} \frac{u_{c}(t)}{P_{t}}, t \geq 1 \\
E_{t-1}\left[v_{t} f\left(\bar{\omega}_{t}\right)\right]=\frac{R_{t-1}^{d}}{1-\frac{E_{t-1}\left[\mu_{t} \bar{\omega}_{t} \phi\left(\bar{\omega}_{t}\right)\right]}{E_{t-1}\left[1-\Phi\left(\bar{\omega}_{t}\right)\right]}} z_{t-1}, t \geq 1 \\
E_{t-1}\left[v_{t} g\left(\bar{\omega}_{t} ; \mu_{t}\right)\right]=R_{t-1}^{d}\left(1-z_{t-1}\right), t \geq 1 \\
\bar{\omega}_{t}=\frac{R_{t-1}^{l}\left(1-z_{t-1}\right)}{v_{t}}, t \geq 0 \\
N_{t}=\frac{v_{t} X_{t-1}}{A_{t} P_{t}}, t \geq 0 \\
Z_{t-1}=z_{t-1} X_{t-1}, t \geq 0 \\
Z_{t-1}=\left(1-\gamma_{t-1}\right) f\left(\bar{\omega}_{t-1}\right) \frac{v_{t-1}}{z_{t-2}} Z_{t-2}, t \geq 1 \\
(1-g) A_{t} N_{t}\left[1-\mu_{t} G\left(\bar{\omega}_{t}\right)\right]=c_{t}, t \geq 0
\end{gathered}
$$

The other equilibrium conditions determine the remaining variables.

Given the path for the price level there is a unique equilibrium for the other variables. To see this, notice that at $t=0$, given the values of $z_{-1}, X_{-1}$ and $R_{-1}^{l}$, the equilibrium for $c_{0}, N_{0}$, $v_{0}, \bar{\omega}_{0}$, can be determined using (51), (55), (56), and (59), for $t=0$. Given these variables, $Z_{-1}=z_{-1} X_{-1}$, and the path for the price level, $P_{t}$, the remaining variables $c_{t}, N_{t}, v_{t}, \bar{\omega}_{t}$, $Z_{t-1}, R_{t-1}^{d}, z_{t-1}, R_{t-1}^{l}, X_{t-1}$ for $t \geq 1$, are determined using (51)-(59), for $t \geq 1$. These are 4 contemporaneous variables and 5 predetermined variables, restricted by 4 contemporaneous conditions and 5 predetermined conditions. If $P_{t}$ are set exogenously, all the other variables have a single solution. Alternatively, we could set exogenously $R_{t-1}^{d}$, plus $P_{t}$ in as many states as $\# S^{t}-\# S^{t-1}$, and again there would be a unique equilibrium.

\section{A.3 Impulse responses to financial shocks}

We present here additional impulse responses to financial shocks in the baseline model where the Friedman rule is optimal. Shocks are serially correlated with a 0.9 correlation coefficient. In all cases, we compare the impulse responses under the optimal policy to those arising under the Taylor rule. 
Figure A1: Impulse responses to an increase in $\sigma_{\omega_{t}}$
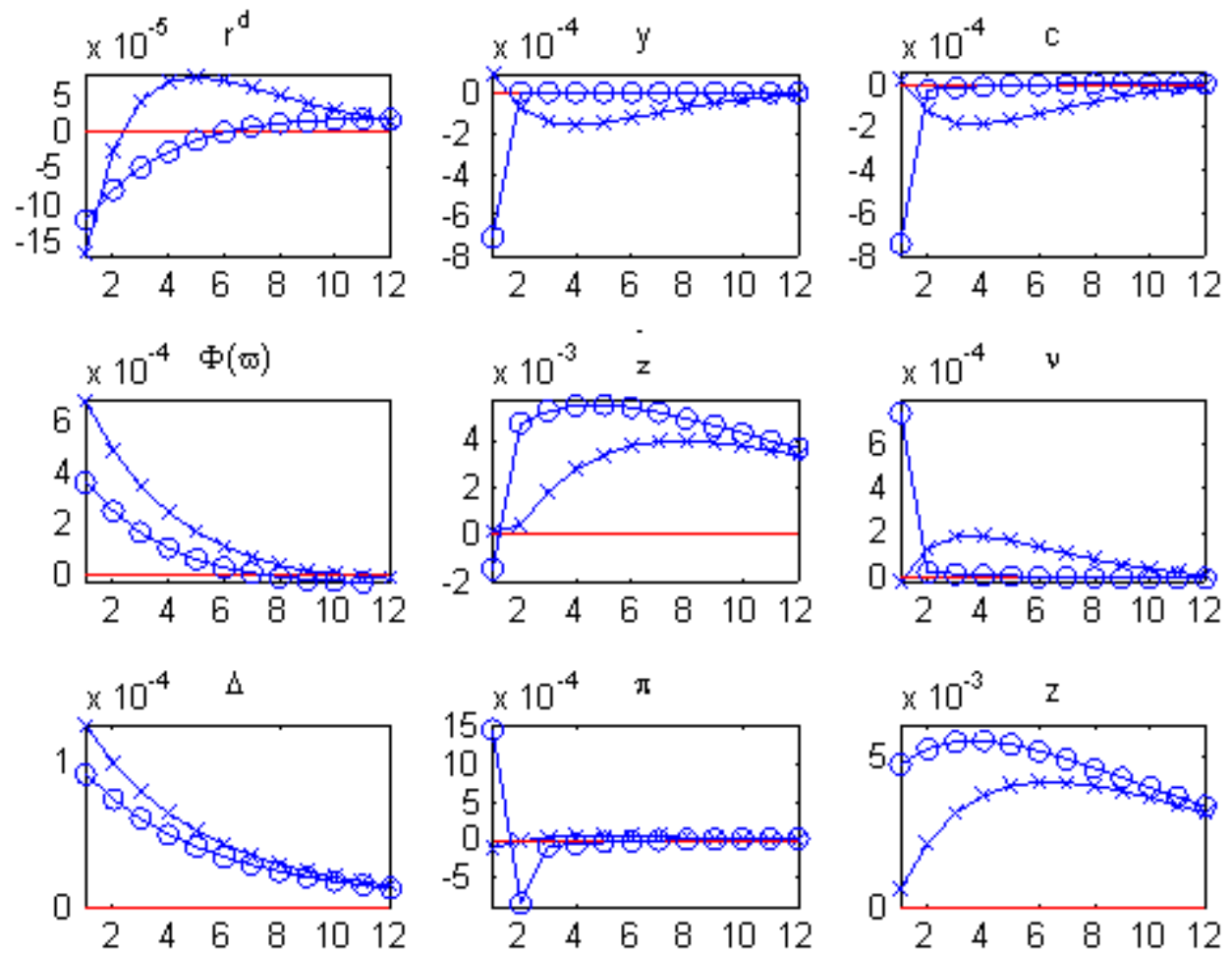

Note: Logarithmic deviations from the non-stochastic steady state. Correlation of the shock: 0.9. The lines with crosses indicate impulse responses under the Taylor rule; the lines with circles report the impulse responses under optimal policy (in the $g>0$ case).

Figure A1 shows the impulse responses to a persistent increase in the riskiness of the economy, i.e. to an increase in the standard deviation of the idiosyncratic shocks $\sigma_{\omega_{i, t}}$. This shock is associated with a prospective worsening of credit conditions and an increase in the bankruptcy rate.

As in the case of the negative shock to the value of internal assets (the $\gamma_{t}$ shock), optimal monetary policy (the line with circles) engineers on impact an increase in the price level to reduce output. The financing conditions stipulated before the shock are ex-post favorable to firms: on impact, the output contraction enables them to make higher profits, so that they will accumulate more internal funds in the following period. This increase in internal funds allows for a fast economic recovery, because a contemporaneous fall in the policy rate neutralizes the effects of the increase in credit spreads. 
The impulse responses to this shock are qualitatively similar to those to a shock in the value of firms' internal assets. The main exception is the response of leverage, which falls after a $\sigma_{\omega_{i, t}}$ shock and increases after a $\gamma_{t}$ shock. The reduction of leverage observed in Figure A1 under optimal policy is a direct result of the impact increase in firms' profits. This is consistent with the temporary increase in the volatility of idiosyncratic shocks at almost unchanged (except on impact) consumption and hours worked. Even if the shock is serially correlated, output and consumption are back at the steady state after one quarter.

Figure A2: Impulse responses to an increase in $\mu_{t}$
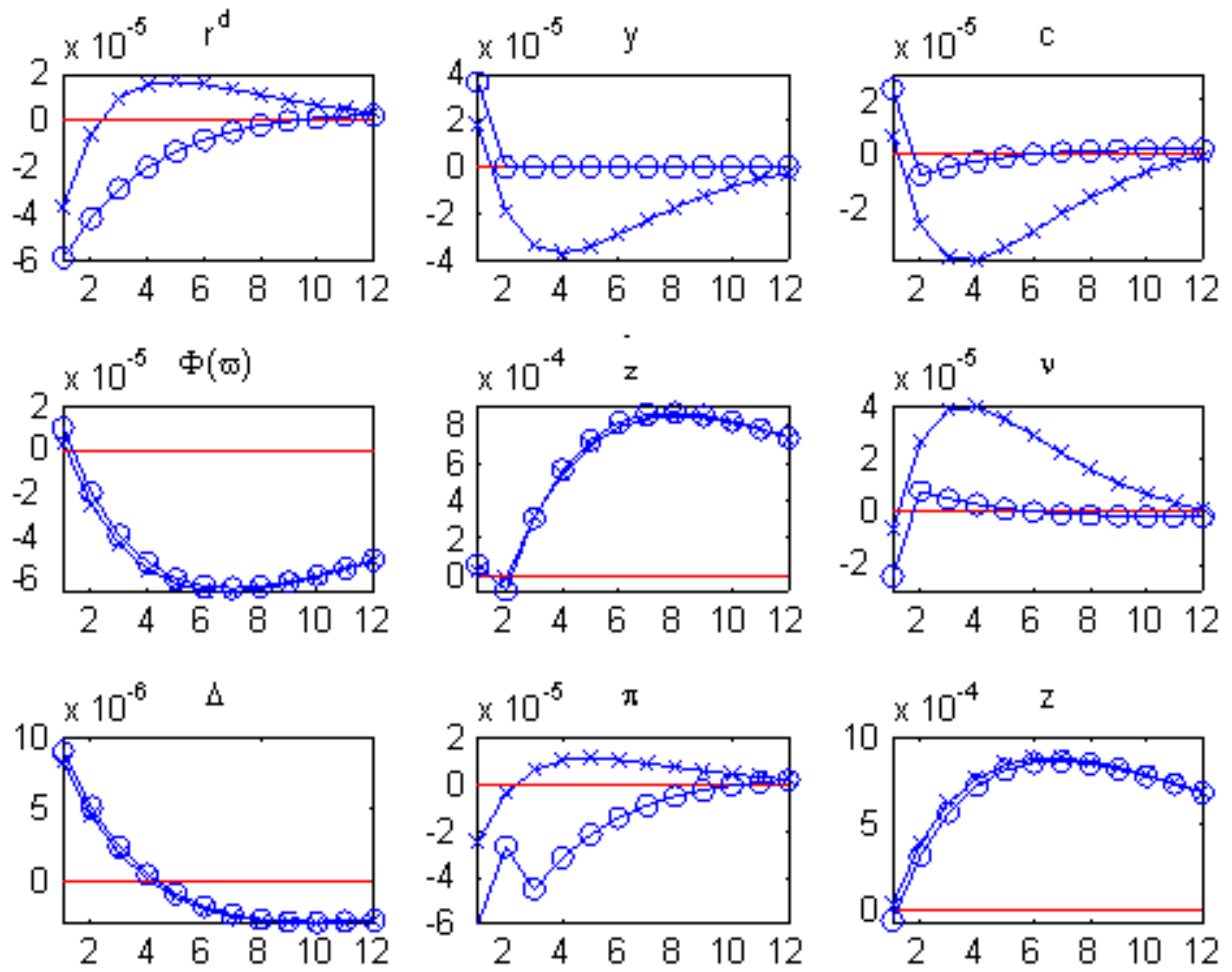

Note: Logarithmic deviations from the non-stochastic steady state. Correlation of the shock: 0.9. The lines with crosses indicate impulse responses under the Taylor rule; the lines with circles report the impulse responses under optimal policy (in the $g>0$ case).

Under the Taylor rule (the line with crosses), there is also a sharp decrease in the deposit rate but, contrary to the optimal policy case, the price level falls on impact. This prevents the initial contraction of output and consumption. As a result, leverage, bankruptcy rates, and 
spreads are higher than under the optimal policy. Internal funds are accumulated at a slower pace and the recession is longer lasting.

Figure A2 plots the responses to an exogenous increase in the proportion of total funds lost in monitoring activities, $\mu_{t}$. This is different from the shock previously analyzed because it mechanically implies a higher waste of resources per unit of output. The optimal policy response is to reduce output in order to minimize the resource loss. If the shock was not serially correlated, this would once again be achieved through an impact increase in the price level. Since the shock is persistent, however, policy needs to manage a trade-off between immediate and future resource losses. An impact increase in the price level would not only immediately reduce output, but it would also lead to more profits and a faster accumulation of internal funds, hence large future losses in monitoring activity as long as $\mu_{t}$ remains high. Compared to this scenario, future losses would be minimized if the price level were instead cut on impact, so as to slow down the accumulation of internal funds.

The trade-off between minimizing current and future losses leads to an impact fall in the price level under optimal policy. This increases the real value of firms' funds and, in turn, allows firms to expand production. The ensuing increases in credit spreads and in bankruptcy rates are countered by a contemporaneous fall in the policy rate. As in the case of the other financial shocks, optimal policy ensures a fast adjustment process: after one quarter, output and hours are back in steady state, and fluctuations in consumption and mark-ups become negligible.

In reaction to a shock to $\mu_{t}$, the price level and the policy interest rate fall less under the Taylor rule. As in the case of other financial shocks, this reaction leads to a more protracted contraction in both output and consumption.

\section{References}

[1] Bernanke, B.S., Gertler, M. and S. Gilchrist. "The Financial Accelerator in a Quantitative Business Cycle Framework." In: Taylor, John B. and Woodford, Michael, eds. Handbook of macroeconomics. Volume 1C. Handbooks in Economics, vol. 15. Amsterdam; New York and Oxford: Elsevier Science, North-Holland, 1999, pp. 1341-93.

[2] Carlstrom, C.T., and T. Fuerst. "Agency Costs, Net Worth, ad Business Fluctuations: A Computable General Equilibrium Analysis.” American Economic Review, 1997, 87, pp. 
893-910.

[3] Carlstrom, C.T., and T. Fuerst. "Agency Costs and Business Cycles." Economic Theory, 1998, 12, pp. 583-597.

[4] Carlstrom, C.T., and T. Fuerst. "Monetary Shocks, Agency Costs and Business Cycles." Carnegie-Rochester Series on Public Policy, 2001, 51, pp. 1-27.

[5] Carlstrom, C.T., T. Fuerst and M. Paustian. "Optimal Monetary Policy in a Model with Agency Costs." Mimeo, 2009.

[6] Christiano, L., R. Motto and M. Rostagno (2003). "The Great Depression and the Friedman-Schwartz Hypothesis.” Journal of Money Credit and Banking 35(6), pp. 11191197.

[7] Curdia, V. and M. Woodford (2009). "Credit Frictions and Optimal Monetary Policy." Mimeo, FRB New York.

[8] De Fiore, F. and O. Tristani (2008). "Optimal Monetary Policy in a Model of the Credit Channel." Mimeo, European Central Bank.

[9] Faia, E (2008). "Optimal Monetary Policy with Credit Augmented Liquidity Cycles." Mimeo, Goethe University Frankfurt.

[10] Faia, E. and T. Monacelli. "Optimal Monetary Policy Rules, Asset Prices and Credit Frictions." Journal of Economic, Dynamics and Control 31, 10, 2007, pp. 3228-3254.

[11] Fisher, I. . "The debt-deflation theory of great depressions." Econometrica I, 1933, pp. 337-357.

[12] Gilchrist, S. and J. Leahy. "Monetary Policy and Asset Prices." Journal of Monetary Economics 49, 2002, pp. 75-97.

[13] Levin, A.T., Natalucci, F., and E. Zakrajsek. "The Magnitude and Cyclical Behavior of Financial Market Frictions." Staff WP 2004-70, Board of Governors of the Federal Reserve System, 2004.

[14] Ravenna, F. and C. Walsh. "Optimal Monetary Policy with the Cost Channel." Journal of Monetary Economics, 53, 2006, pp.199-216. 
[15] Svensson, L. "Money and Asset Prices in a Cash-in-Advance Economy." Journal of Political Economy 93, 1985, pp. 919-944. Reprinted in Kevin D. Hoover, ed., The Economic Legacy of Robert Lucas, Jr, Edward Elgar, 1999.

[16] Woodford, M (2003). "Interest and Prices." Princeton University Press. 


\section{European Central Bank Working Paper Series}

For a complete list of Working Papers published by the ECB, please visit the ECB's website (http://www.ecb.europa.eu).

1086 "Euro area money demand: empirical evidence on the role of equity and labour markets" by G. J. de Bondt, September 2009.

1087 "Modelling global trade flows: results from a GVAR model” by M. Bussière, A. Chudik and G. Sestieri, September 2009.

1088 "Inflation perceptions and expectations in the euro area: the role of news" by C. Badarinza and M. Buchmann, September 2009.

1089 "The effects of monetary policy on unemployment dynamics under model uncertainty: evidence from the US and the euro area" by C. Altavilla and M. Ciccarelli, September 2009.

1090 “New Keynesian versus old Keynesian government spending multipliers” by J. F. Cogan, T. Cwik, J. B. Taylor and V. Wieland, September 2009.

I09I “Money talks” by M. Hoerova, C. Monnet and T. Temzelides, September 2009.

1092 "Inflation and output volatility under asymmetric incomplete information" by G. Carboni and M. Ellison, September 2009.

1093 "Determinants of government bond spreads in new EU countries" by I. Alexopoulou, I. Bunda and A. Ferrando, September 2009.

1094 "Signals from housing and lending booms" by I. Bunda and M. Ca'Zorzi, September 2009.

1095 “Memories of high inflation” by M. Ehrmann and P. Tzamourani, September 2009.

1096 “The determinants of bank capital structure" by R. Gropp and F. Heider, September 2009.

1097 “Monetary and fiscal policy aspects of indirect tax changes in a monetary union” by A. Lipińska and L. von Thadden, October 2009.

1098 "Gauging the effectiveness of quantitative forward guidance: evidence from three inflation targeters" by M. Andersson and B. Hofmann, October 2009.

1099 "Public and private sector wages interactions in a general equilibrium model” by G. Fernàndez de Córdoba, J.J. Pérez and J. L. Torres, October 2009.

I 100 "Weak and strong cross section dependence and estimation of large panels" by A. Chudik, M. Hashem Pesaran and E. Tosetti, October 2009.

I IOI "Fiscal variables and bond spreads - evidence from eastern European countries and Turkey" by C. Nickel, P. C. Rother and J. C. Rülke, October 2009.

I 102 "Wage-setting behaviour in France: additional evidence from an ad-hoc survey" by J. Montornés and J.-B. Sauner-Leroy, October 2009.

I 103 “Inter-industry wage differentials: how much does rent sharing matter?” by P. Du Caju, F. Rycx and I. Tojerow, October 2009. 
I 104 "Pass-through of external shocks along the pricing chain: a panel estimation approach for the euro area" by B. Landau and F. Skudelny, November 2009.

I 105 "Downward nominal and real wage rigidity: survey evidence from European firms" by J. Babecký, P. Du Caju, T. Kosma, M. Lawless, J. Messina and T. Rõõm, November 2009.

I 106 "The margins of labour cost adjustment: survey evidence from European firms" by J. Babecký, P. Du Caju, T. Kosma, M. Lawless, J. Messina and T. Rõõm, November 2009.

I 107 “Interbank lending, credit risk premia and collateral” by F. Heider and M. Hoerova, November 2009.

I 108 "The role of financial variables in predicting economic activity" by R. Espinoza, F. Fornari and M. J. Lombardi, November 2009.

I 109 “What triggers prolonged inflation regimes? A historical analysis.” by I. Vansteenkiste, November 2009.

I I 10 "Putting the New Keynesian DSGE model to the real-time forecasting test" by M. Kolasa, M. Rubaszek and P. Skrzypczyński, November 2009.

I I I "A stable model for euro area money demand: revisiting the role of wealth" by A. Beyer, November 2009.

I I 12 "Risk spillover among hedge funds: the role of redemptions and fund failures" by B. Klaus and B. Rzepkowski, November 2009.

II I 3 "Volatility spillovers and contagion from mature to emerging stock markets" by J. Beirne, G. M. Caporale, M. Schulze-Ghattas and N. Spagnolo, November 2009.

I I 4 "Explaining government revenue windfalls and shortfalls: an analysis for selected EU countries" by R. Morris, C. Rodrigues Braz, F. de Castro, S. Jonk, J. Kremer, S. Linehan, M. Rosaria Marino, C. Schalck and O. Tkacevs.

I I I5 "Estimation and forecasting in large datasets with conditionally heteroskedastic dynamic common factors" by L. Alessi, M. Barigozzi and M. Capasso, November 2009.

I I 16 "Sectorial border effects in the European single market: an explanation through industrial concentration" by G. Cafiso, November 2009.

II 17 "What drives personal consumption? The role of housing and financial wealth" by J. Slacalek, November 2009.

I I 8 "Discretionary fiscal policies over the cycle: new evidence based on the ESCB disaggregated approach" by L. Agnello and J. Cimadomo, November 2009.

I I 9 "Nonparametric hybrid Phillips curves based on subjective expectations: estimates for the euro area" by M. Buchmann, December 2009.

I I 20 "Exchange rate pass-through in central and eastern European member states" by J. Beirne and M. Bijsterbosch, December 2009.

II 2 I "Does finance bolster superstar companies? Banks, venture capital and firm size in local U.S. markets" by A. Popov, December 2009.

I I 22 "Monetary policy shocks and portfolio choice” by M. Fratzscher, C. Saborowski and R. Straub, December 2009.

II 23 "Monetary policy and the financing of firms" by F. De Fiore, P. Teles and O. Tristani, December 2009. 
